\title{
IR studies of the oxygen and carbon precipitation processes in electron irradiated tin-doped silicon
}

\author{
E. N. Sgourou ${ }^{1} \cdot$ T. Angeletos ${ }^{1}$ A. Chroneos ${ }^{2,3} \cdot$ C. A. Londos ${ }^{1}$
}

Received: 1 March 2017 / Accepted: 20 March 2017 / Published online: 7 April 2017

(C) The Author(s) 2017. This article is an open access publication

\begin{abstract}
Oxygen (O) and carbon (C) are key impurities in silicon ( $\mathrm{Si}$ ) and the control of their properties and behavior is an important issue for the microelectronic industry. A number of these properties can be manipulated by isovalent doping. Here we employ Fourier transform infrared (FTIR) spectroscopy to study the evolution of $\mathrm{O}$ and $\mathrm{C}$ concentration as well as the evolution of the oxygen precipitate bands in electron- irradiated tin ( $\mathrm{Sn}$ ) doped $\mathrm{Si}$, subjected to isochronal anneals up to $950^{\circ} \mathrm{C}$. Special attention was given in connecting infrared absorption bands with certain precipitation morphologies. In this study, bands at $1040,1060,1080$ and $1170 \mathrm{~cm}^{-1}$ generally attributed to precipitate morphologies were detected. Using arguments from classical theoretical mechanics we have attributed the $1040 \mathrm{~cm}^{-1}$ band to a structure more close to a spherical morphology, although the 1060 and $1080 \mathrm{~cm}^{-1}$ bands were attributed to structures more close to octahedral and polyhedral morphologies, respectively. Additionally the band at $1170 \mathrm{~cm}^{-1}$ was attributed to platelet precipitates. The effect of $\mathrm{C}$ and $(\mathrm{C}, \mathrm{Sn})$ co-doping $\mathrm{Si}$ in the morphologies of the precipitates bands was investigated in detail. It was found that in the irradiated material $\mathrm{C}$ suppresses the formation of spheroidal precipitates although it enhances the platelet
\end{abstract}

A. Chroneos

ab8104@ coventry.ac.uk

C. A. Londos

hlontos@phys.uoa.gr

1 Solid State Physics Section, University of Athens, Panepistimiopolis Zografos, 15784 Athens, Greece

2 Department of Materials, Imperial College London, London SW7 2AZ, UK

3 Faculty of Engineering, Environment and Computing, Coventry University, Priory Street, Coventry CV1 5FB, UK precipitates, whereas in $\mathrm{Si}$ containing $\mathrm{C}$ and $\mathrm{Sn}$ the opposite behavior was detected. The presence of the two impurities modifies the number of the $\mathrm{O}$ precipitates and affects the relative density among the formed morphologies in $\mathrm{Si}$, determining whether the spheroidal or platelet precipitates will prevail. The phenomenon was discussed taking into consideration the effect of the density of the nucleation sites on the interfacial energy of the precipitates. Furthermore, an inverse annealing stage in the evolution curve of $\mathrm{C}$, namely an increase of $\mathrm{C}$ concentration prior to its complete disappearance was studied. This recovery stage was determined to be enhanced in $(\mathrm{C}, \mathrm{Sn})$ co-doping $\mathrm{Si}$ with relatively low $\mathrm{Sn}$ content although in $\mathrm{Si}$ with high $\mathrm{Sn}$ content the increase of $\mathrm{C}$ is substantially lower. An explanation was suggested based on the ability of the Sn to temporarily trap vacancies, thus affecting the restoration of the $\mathrm{C}$ substitutional atoms in the Si lattice.

\section{Introduction}

$\mathrm{Si}$ remains a mainstram semiconductor material for numerous nanoelectronic, sensor and photovoltaic devices [1-4]. The miniaturization of devices constitutes defect processes very important as their detailed understanding may influence material and/or device properties [5-8]. In particular during the manufacturing of devices thermal annealing, irradiation and doping are among the most usual technological processes of $\mathrm{Si}$, however, they unavoidably introduce defects. Anneals at high temperatures result in precipitates [9-14] of the $\mathrm{O}$ and $\mathrm{C}$ impurities, which are unintentionally introduced during growth in the $\mathrm{Si}$ lattice. Additionally, irradiations introduce defect complexes formed from reactions between primary defects [vacancies $(V)$ and self-interstitials $\left(\mathrm{Si}_{\mathrm{I}}\right)$ ] and 
the $\mathrm{O}$ and $\mathrm{C}$ impurities, including divacancies, oxygenvacancy and oxygen-carbon complexes $[9,12,15]$. There are interactions between the two kinds of defects and in particular radiation defects usually affect the growth and evolution of precipitates [16, 17].

Precipitates and radiation defects influence the yield and the performance of the Si-based devices. Their control and engineering is of importance both from a technological perspective (to improve the output of devices) and for scientific purposes (gain a better understanding of $\mathrm{Si}$ ). To this end, isovalent doping is a widely used way to modify the $\mathrm{Si}$ material properties. Isovalent impurities (such as $\mathrm{Sn}$ ) when introduced in the Si lattice occupy lattice sites and although they have limited effect on the electrical properties, they can modify the physicochemical behavior of the material as a result of the generation of elastic stresses in the lattice. Their presence can have significant consequences [18-26] on the $\mathrm{Si}$ properties and behavior in general. They can enhance the mechanical strength of the material and affect the carrier's mobility offering possibilities for bandgap engineering. Due to the difference of the covalent radius of the isovalent atom with the $\mathrm{Si}$ atom there are also possibilities for lattice parameter engineering. They can affect the micro-defect population enhancing the thermal stability of the material and also improve its radiation hardness. Additionally, they can interact with $V$ and/or $\mathrm{Si}_{\mathrm{I}}$ affecting their concentrations, which is an important factor during the various processing stages of $\mathrm{Si}$. Moreover, they have a strong impact on the formation of $V$ and $\mathrm{Si}_{\mathrm{I}}$ related defects, due to the induced strains in the lattice. Key is the influence of isovalent dopants on the formation of $\mathrm{O}$ and $\mathrm{C}$ precipitates which impacts the fabrication of modern Si-based electronic devices.

$\mathrm{O}$ is an electrically neutral impurity inevitably incorporated during growth in the Si lattice at interstitial sites. In the course of thermal treatments at elevated temperatures supersaturated oxygen impurities tend to aggregate leading to the formation of $\mathrm{SiO}_{x}$ precipitates $[10,11]$. Oxide precipitates can have positive but also negative effects in the functionality of devices [26-31]. Indeed they may be beneficial by acting as sinks for detrimental metallic impurities (internal gettering) and also can enhance the mechanical strength and stability of $\mathrm{Si}$ wafers by preventing dislocation movement. Additionally, they may act in conjunction with surrounding defects, as recombination centers reducing the efficiency of the corresponding devices. Depending upon the thermal history of the material and the temperature of the thermal treatments $\mathrm{O}$ precipitates have different forms and morphologies $[10,11]$ giving rise to a number of IR bands [32-34] in the spectral region of $1000-1300 \mathrm{~cm}^{-1}$, around the strong IR band of oxygen at $1107 \mathrm{~cm}^{-1}$. Notably, the formation of $\mathrm{SiO}_{\mathrm{x}}$ precipitates is accompanied by a volume increase, which induces compressive strains in the
Si lattice. One way that these strains may be relieved is by the emission of $\mathrm{Si}_{\mathrm{I}}$.

$\mathrm{C}$ is an isovalent impurity incorporated in the $\mathrm{Si}$ lattice at substitutional sites and is electrically inactive. On thermal treatments of $\mathrm{Si}$ at elevated temperatures if the $\mathrm{C}$ concentration is above its solubility limit it tends $[12,14$, 35 ] to precipitate leading to the formation of silicon carbide $(\mathrm{SiC})$ or alternatively to the formation of loose $\mathrm{C}-\mathrm{Si}$ aggregates. Both processes lead to a volume reduction and are accompanied by the absorption of $\mathrm{Si}_{\mathrm{I}}$. Since the process of $\mathrm{O}$ precipitation is accompanied by the emission of $\mathrm{Si}_{\mathrm{I}}$, the simultaneous presence of $\mathrm{O}$ and $\mathrm{C}$ in the $\mathrm{Si}$ lattice relieves the strains facilitating the coprecipitation of both impurities. The effect of $\mathrm{C}$ on $\mathrm{O}$ agglomeration process is a complex issue and is investigated by the community due to its important technological interest [35-39]. In the present study, we used C-rich samples as well as samples co-doped with $\mathrm{C}$ and $\mathrm{Sn}$ in an attempt to investigate the impact of $\mathrm{C}$ and $\mathrm{Sn}$ isovalent doping on the oxygen aggregation and the impact of $\mathrm{Sn}$ on $\mathrm{O}$ and $\mathrm{C}$ aggregation in irradiated Si.

Irradiations or/and implantations are quite usually employed in conjunction with thermal treatments in device fabrication processes. However, the formation of irradiation induced defects in $\mathrm{Si}$ involves reactions with $V$ and $\mathrm{Si}_{\mathrm{I}}$. Thus, defects such as $V \mathrm{O}, \mathrm{C}_{\mathrm{i}} \mathrm{O}_{\mathrm{i}}, \mathrm{C}_{\mathrm{i}} \mathrm{C}_{\mathrm{s}}$, and on anneals $V_{\mathrm{n}} \mathrm{O}_{\mathrm{m}}$ and $\mathrm{C}_{\mathrm{i}} \mathrm{O}_{\mathrm{i}} \mathrm{Si}_{\mathrm{I}}$ clusters $[9,12,40-44]$ affect the production and the balance of the $V$ and the $\mathrm{Si}_{\mathrm{I}}$ 's concentrations. Since these primary defects play important role in $\mathrm{O}$ and $\mathrm{C}$ aggregation processes [9-14, 45-48] it is necessary to study such processes in irradiated material. Notably, $V \mathrm{O}$ and $\mathrm{VO}_{2}$ defects have been suggested [49] to act as nucleation sites for $\mathrm{O}$ precipitation.

As we mentioned above, doping with isovalent impurities is a judicious choice to control and improve the quality of $\mathrm{Cz}-\mathrm{Si}$ material for device fabrication. Sn doping is also important for the Si material properties. As $\mathrm{Sn}$ is larger than $\mathrm{Si}$ it readily attracts $V$ and this reduces the formation of $V \mathrm{O}$ and $V \mathrm{O}_{2}$ defects [50-52]. Additionally, Sn suppresses the formation of C-related defects [51] verifying the results of previously reported photoluminescence studies [28, 53]. In this framework Sn doping has been suggested as a way to enhance the radiation hardness of Si especially for applications related with solar cells and detectors operating in radiation environments [54, 55]. Additionally, since Sn attracts $V$ and $\mathrm{C}$ binds with $\mathrm{Si}_{\mathrm{I}}, \mathrm{Si}$ codoping with $\mathrm{Sn}$ and $\mathrm{C}$ has been proposed [50] to further increase its radiation hardness and may be used as a tool to assess the degradation of Si-based devices. Furthermore, the presence of $\mathrm{Sn}$ significantly affects the formation of thermal donors and $\mathrm{O}$ precipitates formed on thermal treatments at elevated temperatures [28, 56-60].

In the present study we used FTIR spectroscopy to explore the effect of $\mathrm{Sn}$ isovalent doping on the evolution 
of $\mathrm{O}$ and $\mathrm{C}$ impurities in carbon-rich $\mathrm{Cz}-\mathrm{Si}$ subjected to electron irradiation and subsequent isochronal anneals up to $950^{\circ} \mathrm{C}$. Considering co-doping pairs $(\mathrm{C}, \mathrm{Sn})$ in $\mathrm{Si}$ will help us gain a more complete understanding of mechanisms that govern $\mathrm{O}$ and $\mathrm{C}$ precipitation processes as well as the ways that $\mathrm{Sn}$ isovalent dopants affect these processes. Importantly, since $V$ and $\mathrm{Si}_{\text {I }}$ play [61-67] a key role in the $\mathrm{O}$ and $\mathrm{C}$ precipitation processes we can reversibly deepen our understanding on the mechanisms through which these primary defects affect the agglomeration of $\mathrm{O}$ and $\mathrm{C}$ impurities in Si treated at elevated temperatures. Also it could enhance the opportunities for technological improvements of Si providing an engineering strategy for thermal defects that could be employable to analogous systems. Isovalent dopants due to their larger size introduce stains in the $\mathrm{Si}$ lattice which affect the $\mathrm{O}$ and $\mathrm{C}$ aggregation processes. Notably, the application of high hydrostatic stress has been determined [68, 69] to have also a significant effect on the $\mathrm{O}$ agglomeration processes and comparison of the relative results would enhance our understanding of the two phenomena.

\section{Experimental methodology}

Samples used in the present study were cut from prepolished $\mathrm{Cz}-\mathrm{Si}$ wafers with dimensions $10 \times 15 \times 2 \mathrm{~mm}^{3}$ and contained C. Besides a sample labeled Cz-Si with a low amount of $\mathrm{C}$ and a sample labeled $\mathrm{Cz}-\mathrm{Si}: \mathrm{C}$ with high $\mathrm{C}$ content we also used other $\mathrm{Cz}-\mathrm{Si}$ samples contained carbon and doped with $\mathrm{Sn}$ (labeled respectively as $\mathrm{Cz}$ $\mathrm{Si}: \mathrm{C}, \mathrm{Sn}_{\mathrm{L}}$ and $\left.\mathrm{Cz}-\mathrm{Si}: \mathrm{C}, \mathrm{Sn}_{\mathrm{H}}\right)$. The oxygen $\left(1107 \mathrm{~cm}^{-1}\right)$ and carbon $\left(605 \mathrm{~cm}^{-1}\right)$ concentrations were calculated by infrared spectroscopy using calibration coefficients $[10,12]$ $3.14 \times 10^{17} \mathrm{~cm}^{-2}$ and $1.0 \times 10^{17} \mathrm{~cm}^{-2}$, respectively. The concentrations of the isovalent dopants in the samples were measured by secondary ion mass spectrometry (SIMS) and the values were given by the supplier's certificate. The samples were irradiated with $2 \mathrm{MeV}$ electrons with a fluence of $1 \times 10^{18} \mathrm{~cm}^{-2}$, at $\sim 70^{\circ} \mathrm{C}$, using the Dynamitron accelerator at Takasaki-JAERI (Japan). Information regarding impurities concentrations is given in Table 1. Notably, the
$\mathrm{O}$ and $\mathrm{C}$ concentrations in the $\mathrm{Cz}-\mathrm{Si}: \mathrm{C}, \mathrm{Sn}_{\mathrm{H}}$ after the irradiation were higher than prior to irradiation. The increase of $\mathrm{C}$ was attributed [70] to the existence of $\mathrm{Sn}_{\mathrm{s}} \mathrm{C}_{\mathrm{s}}$ complexes in the $\mathrm{Si}$ lattice, as a result of the growth procedure, which in the course of irradiation transform to $\mathrm{Sn}_{\mathrm{s}} \mathrm{C}_{\mathrm{i}}$ complexes by reacting with $\mathrm{Si}_{\mathrm{I}}\left(\mathrm{Sn}_{\mathrm{s}} \mathrm{C}_{\mathrm{s}}+\mathrm{Si}_{\mathrm{I}} \rightarrow \mathrm{Sn}_{\mathrm{s}} \mathrm{C}_{\mathrm{i}}\right)$. The $\mathrm{Sn}_{\mathrm{s}} \mathrm{C}_{\mathrm{i}}$ defect is unstable at the temperature of irradiation and breaks to its constituent defects $\left(\mathrm{Sn}_{\mathrm{s}} \mathrm{C}_{\mathrm{i}} \rightarrow \mathrm{Sn}_{\mathrm{s}}+\mathrm{C}_{\mathrm{i}}\right.$ ). Then $\mathrm{C}_{\mathrm{i}}$ being mobile at these temperatures transform to $\mathrm{C}_{\mathrm{s}}\left(\mathrm{C}_{\mathrm{i}} \rightarrow \mathrm{C}_{\mathrm{s}}+\mathrm{Si}_{\mathrm{I}}\right)$ resulting to the increase of $\mathrm{C}_{\mathrm{s}}$. Additionally, the observed increase of $\mathrm{O}_{i}$ after the irradiation can be attributed [70] in the presence of $\mathrm{Sn}_{\mathrm{s}} \mathrm{O}_{\mathrm{i}}$ complexes in the $\mathrm{Si}$ lattice which as a result of irradiation lead to the release of more $\mathrm{O}_{i}$ atoms through the reactions $\left(\mathrm{Sn}_{\mathrm{s}} \mathrm{O}_{\mathrm{i}}+\mathrm{Si}_{\mathrm{I}} \rightarrow \mathrm{Sn}_{\mathrm{i}} \mathrm{O}_{\mathrm{i}}\right.$ and $\left.\mathrm{Sn}_{\mathrm{i}} \mathrm{O}_{\mathrm{i}} \rightarrow \mathrm{Sn}_{\mathrm{i}}+\mathrm{O}_{\mathrm{i}}\right)$ resulting finally to the increase of the $\mathrm{O}_{i}$. In the case of the sample $\mathrm{Cz}-\mathrm{Si}: \mathrm{C}, \mathrm{Sn}_{\mathrm{L}}$ with low $\mathrm{Sn}$, only the $\mathrm{O}$ concentration was observed to increase after the irradiation. Seemingly, the release of $\mathrm{C}$ atoms from pre-existed $\mathrm{Sn}_{\mathrm{s}} \mathrm{C}_{\mathrm{s}}$ complexes in this sample is not enough to cover the loss of $\mathrm{C}$ due to the formation of $\mathrm{C}_{\mathrm{i}} \mathrm{O}_{\mathrm{i}}$ and $\mathrm{C}_{\mathrm{i}} \mathrm{C}_{\mathrm{s}}$ defects as a result of the irradiation, so that overall the final $\mathrm{C}$ concentration is lower than that prior to irradiation.

After the irradiation, all the samples were subjected to $20 \mathrm{~min}$ isochronal anneals up to $950{ }^{\circ} \mathrm{C}$ in open furnaces with a step of $\sim 10^{\circ} \mathrm{C}$. Following every annealing step, the IR spectra were recorded at room temperature using an FTIR spectrometer (JASCO-470 plus) with a resolution of $1 \mathrm{~cm}^{-1}$. The two phonon background absorption was subtracted from each spectrum by using a float-zone sample of equal thickness.

\section{Results and discussion}

As a result of the thermal anneals the shape of the $\mathrm{O}$ band at $1107 \mathrm{~cm}^{-1}$, as the temperature increases, becomes distorted due to the presence of other bands emerging in the spectra in the same frequency range and originating from $\mathrm{O}$ precipitates [11-13, 71]. The contribution of each individual precipitate band to the total signal can be recovered by making computer deconvolution using Lorentzian profiles.
Table 1 Information of the samples used in this work

\begin{tabular}{llllccc}
\hline Sample name & {$[\mathrm{Sn}]\left(10^{18} \mathrm{~cm}^{-3}\right)$} & {$\left[\mathrm{C}_{\mathrm{s}}\right]_{\mathrm{o}}\left(10^{17} \mathrm{~cm}^{-3}\right)$} & $\begin{array}{l}{\left[\mathrm{C}_{\mathrm{s}}\right]_{\mathrm{a}} \cdot} \\
\left(10^{117} \mathrm{~cm}^{-3}\right)\end{array}$ & {$\left[\mathrm{O}_{\mathrm{i}}\right]_{\mathrm{o}}\left(10^{17} \mathrm{~cm}^{-3}\right)$} & $\begin{array}{l}{\left[\mathrm{O}_{\mathrm{i}}\right]_{\mathrm{a}_{\mathrm{i}}} \cdot} \\
\left(10^{17} \mathrm{~cm}^{-3}\right)\end{array}$ & $\begin{array}{l}{\left[\mathrm{C}_{\mathrm{s}}\right]_{\max }} \\
\left(10^{17} \mathrm{~cm}^{-3}\right)\end{array}$ \\
\hline $\mathrm{Cz}-\mathrm{Si}$ & - & 0.5 & $<0.2$ & 9.5 & 8.8 & - \\
$\mathrm{Cz}-\mathrm{Si}: \mathrm{C}$ & - & 2.2 & 1.2 & 10.0 & 8.9 & 1.5 \\
$\mathrm{Cz}-\mathrm{Si}: \mathrm{C}, \mathrm{Sn}_{\mathrm{L}}$ & 0.3 & 4.7 & 2.5 & 9.6 & 10.7 & 3.7 \\
$\mathrm{Cz}-\mathrm{Si}: \mathrm{C}, \mathrm{Sn}_{\mathrm{H}}$ & 9.0 & 2.0 & 2.6 & 9.2 & 9.7 & 2.5 \\
\hline
\end{tabular}

The concentrations of $\mathrm{Sn}$ as well as of $\mathrm{O}_{\mathrm{i}}$ and $\mathrm{C}_{\mathrm{s}}$ before (o) and after irradiation (a.i.) for the $2 \mathrm{MeV}$ electron irradiation at a fluence of $1 \times 10^{18} \mathrm{e} \cdot \mathrm{cm}^{-2}$, at $\mathrm{T}_{\text {irr }} \approx 70^{\circ} \mathrm{C}$. $[\mathrm{C}]_{\max }$ represents the maximum concentration of carbon in the course of the isochronal anneals sequence 
Figure 1 is the Lorentzian deconvolution of the $\mathrm{O}$ band at $1107 \mathrm{~cm}^{-1}$ for characteristic temperatures of the annealing process for the Cz-Si (1(a)), Cz-Si:C (1(b)), Cz-Si:C,Sn (1(c)) and $\mathrm{Cz}-\mathrm{Si}: \mathrm{C}, \mathrm{Sn}_{\mathrm{H}}$ (1(d)) samples, respectively. The analysis shows the existence of five additional bands at around 1000, 1040, 1060, 1080 and $1170 \mathrm{~cm}^{-1}$. Notably, the bands found by the above analysis of the Lorentzian deconvolution are physically meaningful since there is ample experimental evidence, from various measurements also at low temperature, that the bands are related with oxygen precipitate morphologies [11-13, 71-76]. Initially, we will discuss the origin of each particular band in an attempt

\section{$\mathrm{Cz}-\mathrm{Si}$}
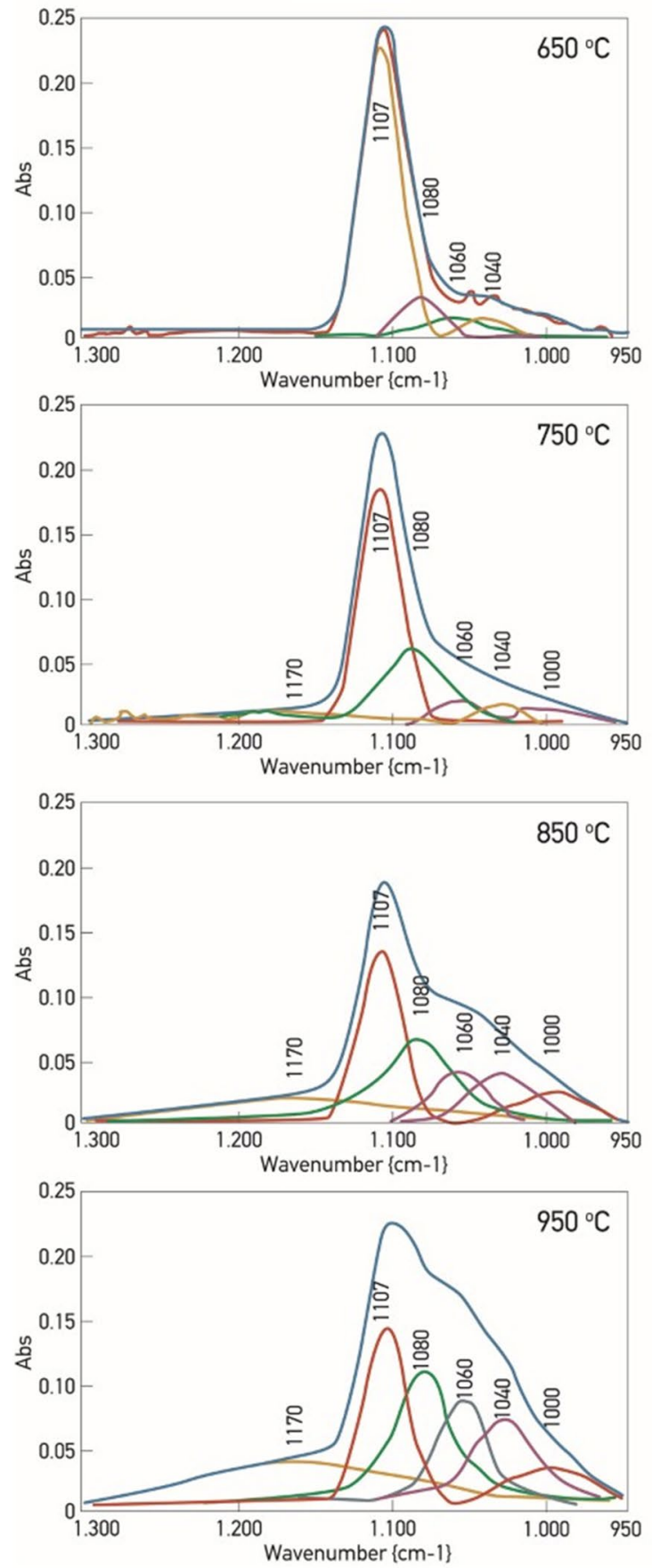

(a)
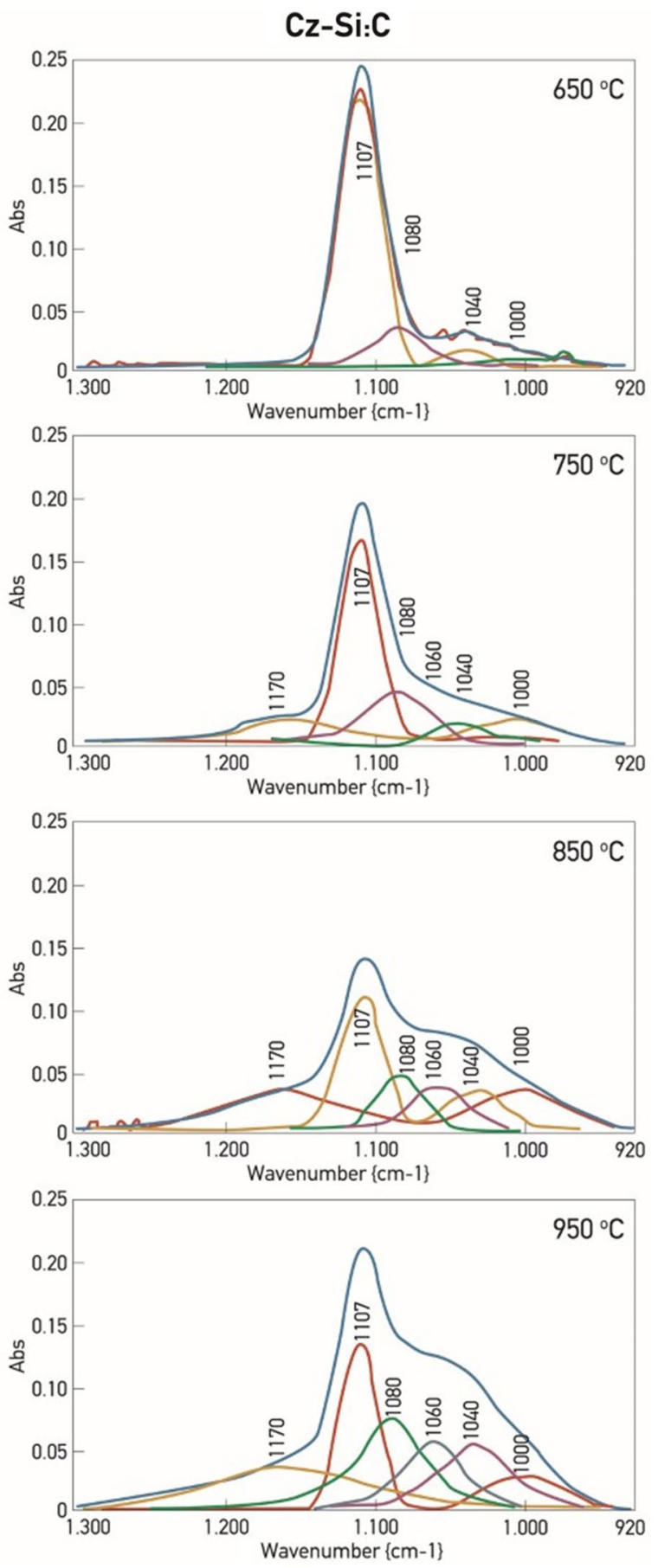

(b)

ous characteristic temperatures in the course of the $20 \mathrm{~min}$ isochronal anneals sequence in the temperature range between $\mathrm{RT}$ and $950{ }^{\circ} \mathrm{C}$
Fig. 1 Deconvolution of the IR band region around $1107 \mathrm{~cm}^{-1}\left(\mathrm{O}_{\mathrm{i}}\right)$ into Lorentzian profiles for the $\mathrm{Cz}-\mathrm{Si}(\mathbf{a})$, the $\mathrm{Cz}-\mathrm{Si}: \mathrm{C}(\mathbf{b})$, the $\mathrm{Cz}$ $\mathrm{Si}: \mathrm{C}, \mathrm{Sn}_{\mathrm{L}}(\mathbf{c})$ and the $\mathrm{Cz}-\mathrm{Si}: \mathrm{C}, \mathrm{Sn}_{\mathrm{H}}(\mathbf{d})$ samples after irradiation at vari- 

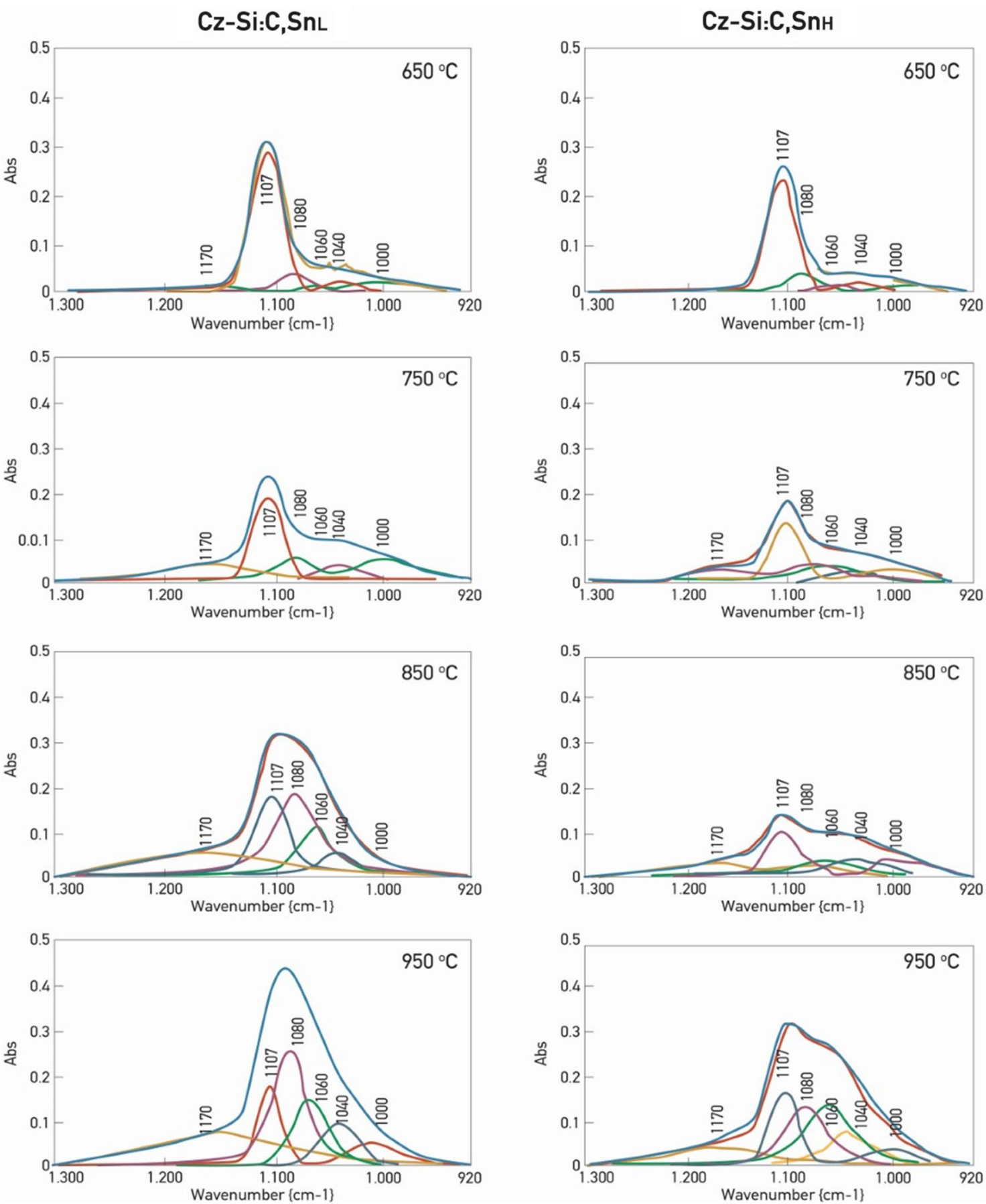

(c)

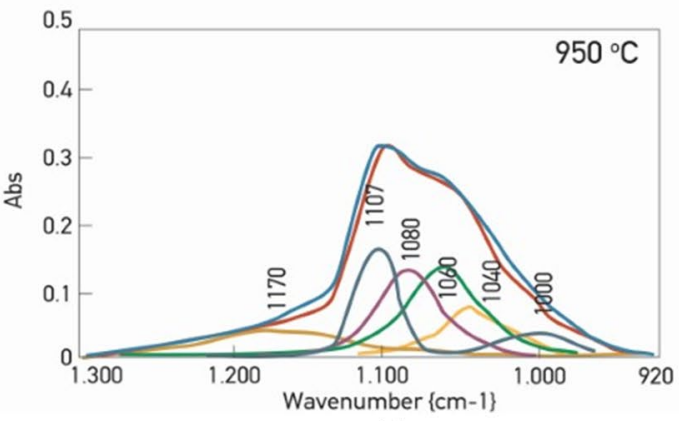

(d)

Fig. 1 (continued)

to correlate the absorption band frequencies with the shape and morphology of certain $\mathrm{O}$ precipitate structures.

A mathematical way to study the behavior of a precipitate is to consider its shape as an ellipsoid with three main axes $\left(a_{1}, a_{2}, a_{3}\right)$. The various ratios of the main axes can properly describe all the possible common shapes of precipitates that is disc, sphere, and needle $[72,77,78]$. This shape mainly depends on the total free energy $F$ of the structure, that is the sum of the strain and the surface (interfacial) energy $[48,79]$. The smaller the size of a precipitate, the smaller the ratio of the strain energy to the surface energy. Obviously, as long as the size of the precipitate is small, the dominant energy term is the surface energy which favors in general a spheroidal morphology, since this 
morphology minimizes this term. When the size of a precipitate increases, the dominant energy term is the strain energy which favors a platelet morphology. This morphology minimizes the ratio of the strain to the surface energy. Thus, platelet seems to be more favorable in comparison with spherical for the case of larger size precipitates [79].

In order to correlate the IR absorption spectroscopic profile of the small $\mathrm{SiO}_{2}$ precipitates with their morphology, $\mathrm{Hu}$ employed [77] a model based on a theory of average dielectric function to describe the absorption in terms of polarization of the precipitate structure in $\mathrm{Si}$. It was found that the IR band at $1230 \mathrm{~cm}^{-1}$ can be attributed to platelets [77]. In addition, Sassella et al. [72] assuming that the precipitate shape is modeled as a rotation ellipsoid with varying diameter/thickness ratio $m$ (i.e. $m=1$ for spheres and $m>>1$ for thin discs) and applying effective medium theory (EMT) simulations showed that disc shaped precipitates gives a band around $1254 \mathrm{~cm}^{-1}$ while the spherical shaped precipitates are responsible [72] for a number of IR bands in the range of $1050-1150 \mathrm{~cm}^{-1}$. Notably, the band at $1230 \mathrm{~cm}^{-1}$ is not present in our spectra. This point will be discussed in detail below. The determination of the elastic field of an ellipsoidal inclusion and its dependence on the shape of the related structure was thoroughly studied theoretically by Eshelby [80]. Using the results of this investigation, Voronkov [79] has calculated the critical value of the term $P^{2} R$, where $R$ is the particle radius and $P$ is the actual pressure created as a result of the induced strain due to the difference between the volume $V_{\mathrm{p}}$ of the non-strained particle and the volume $V_{\mathrm{c}}$ of the non-strained matrix cavity. One of the conclusions of this analysis was that the total free energy $F$ of a spheroidal oxide precipitate depends on the aspect ratio $\alpha$, namely the ratio of the smaller half axis $\mathrm{c}$ to the larger half axis a of the structure. Additionally, it was determined [81, 82] that the higher the annealing temperature (or the longer the annealing time, in the case of isochronal anneals) the larger the radius $R$ of the precipitate and consequently the larger the pressure $P$ of the structure. Figure 1a-d in Ref. 79 describe the changes of the curves of the total free energy of a precipitate structure in relation with the aspect ratio for four values of pressure $P$ or equivalently for four respective values of annealing temperature. For example, Fig. 1a refers to a low value of $P$ or annealing temperature, at an earlier stage of the precipitation process, although, Fig. 1d refers to a larger value of $P$ or annealing temperature at a later stage of the process. By inspection of Fig. 1 one can observe that for low annealing temperatures (Fig. 1a) there is only one minimum of the total free energy characterized by a specific value of the curvature, which corresponds to the spherical morphology $(\alpha \sim 1)$. As the temperature increases the total free energy curve gradually changes and a second local minimum (Fig. 1b), appears at a lower value of $\alpha(\sim 0.4)$, corresponding generally to a spheroidal morphology. The position of this minimum shifts continuously to smaller values of $\alpha$ as the annealing temperature becomes larger (Fig. 1c) and the symmetry of the structure is lowered. The precipitate is gradually transformed to a more asymmetric structure $(\alpha \sim 0.2)$, corresponding to platelet morphology. The minimum of the total free energy is now characterized by a larger value of curvature than that of the spherical (compare Fig. 1a, d).

From classical theoretical mechanics, at every stable equilibrium site (minimum of the energy vs. space coordinate diagram), for "small" displacements $\delta \alpha=\left(\alpha-\alpha_{\mathrm{o}}\right)^{2}$ from the equilibrium position $a_{\mathrm{o}}$, the potential curve can be approximated by a unique parabolic curve $U(a)=(1 / 2) \cdot k \cdot\left(a-a_{\mathrm{o}}\right)^{2}$, where $k$ stands for the term $\left[\partial^{2} U(\alpha \alpha) / \partial \alpha^{2}\right] \alpha_{\mathrm{o}}$ which is proportional to the value of curvature of the potential curve at $a=a_{0}$. Accordingly, since the frequency $\omega$ is proportional to the square root of $k$, it is expected that the absorption band frequency of the platelet-shaped precipitates to be higher than that of the spheroidal-shaped. In general, a spheroidal morphology encompasses either spherical precipitates (structure with the higher symmetry), or octahedral precipitates (structure with lower symmetry) or polyhedral precipitates (structure with even lower symmetry). Taking the ratio of the absorption band frequencies called $\omega_{\text {sph }}$ and $\omega_{\text {plat }}$, for the spheroidal and the platelet precipitate morphologies with masses $M_{\text {sph }}$ and $M_{\text {plat }}$ respectively, we have:

$$
\begin{aligned}
& \left\{\left(\partial^{2} U\left(\alpha_{o}\right) / \partial \alpha^{2}\right)_{\text {plat }} /\left(\partial^{2} U\left(\alpha_{o}\right) / \partial \alpha^{2}\right)_{\text {sph }}\right\}=\mathrm{k}_{\text {plat }} / k_{\text {sph }} \\
& \quad=M_{\text {plat }} \omega_{\text {plat }}{ }^{2} / M_{\text {sph }} \omega_{\text {sph }}{ }^{2} \text { or } \quad \omega_{\text {plat }} / \omega_{\text {sph }} \\
& \quad=\left[\left(M_{\text {sph }} / M_{\text {plat }}\right) \cdot\left\{\left(\partial^{2} U\left(\alpha_{o}\right) / \partial \alpha^{2}\right)_{\text {plat }} /\left(\partial^{2} U\left(\alpha_{o}\right) / \partial \alpha^{2}\right)_{\text {sph }}\right\}\right]^{1 / 2}
\end{aligned}
$$

Considering again Fig. 1 of Ref. 79, the total free energy curve of an ellipsoid precipitate at the region of the total minimum was fitted with a polynomial function $\mathrm{f}$ $(x)=\mathrm{a}_{0}+\mathrm{a}_{1} x+\mathrm{a}_{2} x^{2}+\mathscr{Q}\left(x^{3}\right)$. The optimum fitting was reached by using a parabolic function $\left(\mathrm{a}_{\mathrm{n}}=0\right.$ for $\left.\mathrm{n} \geq 3\right)$. At low annealing temperatures (refer to Fig. 1a) the size of the precipitate structure is small. At higher annealing temperatures (refer to Fig. 1b-d) the size of the precipitate is expected to increase gradually. Notably, the curvature of the minimum of the total free energy curve has a greater value in the case of Fig. 1d as compared to the minimum of the Fig. 1a. Additionally, the position of the minimum corresponds to a lower aspect ratio in the case of Fig. 1d. Furthermore, comparing spheroidal and platelet morphology precipitates (by fitting the curves in Fig. 1c, d) the corresponding parabolic functions are derived:

$$
\begin{aligned}
f_{\text {sph }}(x) & =654 a^{2}-467 a+78, a_{\mathrm{o} \mathrm{sph}} \\
& =0.35,\left[\partial^{2} U\left(\alpha_{o}\right) / \partial \alpha^{2}\right]_{\mathrm{sph}}=1308 \\
f_{\text {plat }}(x) & =7183 a^{2}-325 a+253, a_{\mathrm{oplat}} \\
& =0.23,\left[\partial^{2} U\left(\alpha_{o}\right) / \partial \alpha^{2}\right]_{\text {plat }}=14366
\end{aligned}
$$


where $f_{\text {sph }}(x)$ stands for spheroidal and $f_{\text {plat }}(x)$ for platelets.

Thus, from Eq. (1) we have:

$\omega_{\text {plat }} / \omega_{\text {sph }}=3.32 \cdot\left(M_{\text {sph }} / M_{\text {plat }}\right)^{1 / 2}$

Now, we assume that the density of a spheroidal structure is not much different from that of a platelet structure since the bond length of $\mathrm{SiO}_{2}$ unit is practically the same between the two morphologies. Notably, the difference of the actual pressure $\mathrm{P}$ in the oxide, between spheroidal and platelet structures is $~ 9 \%$ (compare Fig. 1c, $d$ in Ref. 79). This change of $\mathrm{P}$ is shared between all the $\mathrm{SiO}_{2}$ units in the precipitate structure and therefore the actual change of the bond length of a single $\mathrm{SiO}_{2}$ unit is practically negligible. Thus, the ratio of the masses $m_{\text {plat }} / m_{\text {sph }}$ could be taken approximately equal to the ratio of the volumes $V_{\text {plat }} / V_{\text {sph }}$. These volumes have been measured by transmission electron microscopy (TEM) [83-85] and calculated by using Ham's theory [86]. The corresponding values are $V_{\text {sph }} \approx 10 \mathrm{~nm}^{3}$ and $V_{\text {plat }} \approx 100 \mathrm{~nm}^{3}$ respectively, from which we receive $V_{\text {sph }} / V_{\text {plat }} \approx 0.1$. Replacing the above values of the volume ratio instead of the mass ratio in Eq. 2 we finally have:

$\omega_{\text {plat }} / \omega_{\text {sph }} \approx 1.05$

A final comment regarding relation (2) deserves to be noted. It is known that for the case of molecules, the frequency is proportional to the inverse square root of the mass of the molecule. Our analysis shows that this relation could be extended also for the precipitate masses. This is reasonable given that the frequency of the precipitate morphology depends on both the size and the shape, and not on the chemical bonding of the structure $[11,87]$.

In the present experiment, Lorenzian profiling was employed in the region $950-1300 \mathrm{~cm}^{-1}$ around the $1107 \mathrm{~cm}^{-1} \mathrm{O}$ band. IR bands at $\omega_{1}=1170, \omega_{2}=1080$, $\omega_{3}=1060$ and $\omega_{4}=1040 \mathrm{~cm}^{-1}$ were related to $\mathrm{O}$ precipitates [72-76]. Before proceeding with the identification of these bands, it is necessary to discuss the absence of the $1230 \mathrm{~cm}^{-1}$ band from our spectra. This band has been attributed $[32,71,77,87]$ to platelet-shaped precipitates. The structure becomes IR active only when its size is smaller than $0.36 \mu \mathrm{m}$ and it is shifted towards lower wavenumbers when the precipitates structure becomes more spheroidal [77]. In agreement with the above, it has been reported [88] that a thin oblate spheroid (simplification of a platelet) with an aspect ratio $\sim 0.01$ gives rise to an absorption band at $1227 \mathrm{~cm}^{-1}$. The gradually change of the morphology from plate-like to more spheroidal shapes with larger aspect ratio shifts the frequency to lower wavenumbers [88]. Remarkably however, the $1230 \mathrm{~cm}^{-1}$ band has not been detected in the spectra in a number of previous experimental works [32, 37, 71, 87, 89-91]. It is important to note that the dominant factors that determine the morphology of a precipitate structure, are the thermal treatment process as well as the initial oxygen and carbon concentration of the Si material.

Regarding oxygen impurity, it has been determined [92] that the initial oxygen concentration of the sample plays a key role in defining the prevailing morphology of the formed precipitates. In particular, when this concentration is lower than a critical value, precipitates are mainly octahedral and/or polyhedral structures due to the very low oxygen supersaturation. No platelet precipitates can be formed under these conditions [92]. In agreement with this, it has been reported [32] that on samples submitted to thermal treatments, the $1230 \mathrm{~cm}^{-1}$ band of platelets appears in the spectra of high oxygen concentration samples, although in two samples of low oxygen concentration the band is absent.

Regarding thermal treatments, it has been observed [11, 87, 89, 93-97] that when the samples were subjected to long term pre-annealing treatments at low temperatures $[11,87-89,93-95]$ i.e. at $\sim 750^{\circ} \mathrm{C}$ or even lower temperatures $[37,90,96]$ i.e. at $\sim 450-650^{\circ} \mathrm{C}$ an emission of a large amount of $\mathrm{Si}_{I}$ takes places and rod-like defects are formed [90]. On further anneals at higher temperatures these defects act preferentially as nuclei for oxygen impurities to precipitate [90] rather than forming new platelets precipitates or precipitating on already existing platelets. In essence, this two-step annealing sequence leads to a suppression of platelet precipitate formation [90]. Additionally, it was found [90] that in the case of long term preannealing treatments at low temperatures, the size and density of rod-like defects increases. At higher temperature anneals these rod-like defects are converted into stacking faults relieving the platelet suppression [11, 87, 90]. However, at these higher temperatures firstly no more sufficient nucleation of oxygen precipitates occur and secondly some already existing small precipitate nuclei disappear [90]. In essence, no platelets form under these circumstances. Admittedly, for longer pre-annealing time durations, only large platelets which survived through the above suppression effect may exist [90]. If these structures however have size larger than $0.36 \mu \mathrm{m}$ they do not give any absorption [77] at the $1230 \mathrm{~cm}^{-1}$. Besides, any process initiated from small nuclei which survived from the shrinking or the coalescence effect [90] and could potentially lead to the formation of platelet-shaped precipitates at higher temperatures does not occur. Instead, these small nuclei prefer to transform into precipitate structures of higher aspect ratio or they dissolve and form microprecipitates [87, 90]. Significantly enough, a transition between plate-like morphologies and morphologies with larger aspect ratio, for instance octahedral, was previously determined [87, 91]. It is therefore concluded that the enhancement of the density 
of microdefects, introduced by the low temperature preannealing treatments, creates the conditions for the suppression of platelets morphologies. Furthermore, in the case of high temperature pre-annealing treatment the formation of microdefects is not favorable and therefore platelets could be formed [96]. In summary, when the samples are subjected to low temperatures pre-annealing treatment followed by a high temperature thermal anneal, the $1230 \mathrm{~cm}^{-1}$ band is generally not detected.

Regarding carbon, previous works have shown [37, 89, 93-96] that in carbon-doped Cz-Si samples subjected to various heat treatments the $1230 \mathrm{~cm}^{-1}$ was not observed. Carbon presence suppresses the formation of large size oxygen precipitates and favors the formation of higher density precipitates but of smaller size [93]. There are two key points. In one hand carbon releases strains in the lattice and on the other hand platelet-shaped precipitates are stabilized only when the local strain is high. As a result, the presence of carbon forces platelet structures to transform [94] into polyhedral structures, which have generally a larger aspect ratio. Importantly, a band at $\sim 1180 \mathrm{~cm}^{-1}$ has been attributed $[71,75,76,78]$ to platelet shaped precipitates.

In the present study, irradiated Cz-Si samples containing carbon were subjected to isochronal anneals starting from low temperatures $\sim 100$ up to $\sim 950^{\circ} \mathrm{C}$. From the above analysis, it can be concluded that this isochronal annealing sequence could be simulated with a two-step thermal treatment where the first step occurs at relatively low $\mathrm{T}$ and the second step at relative high $\mathrm{T}$. In agreement and with ref. 37 the $1230 \mathrm{~cm}^{-1}$ band is absent. Instead, a band at $1170 \mathrm{~cm}^{-1}$ found in our spectra is related to platelet morphologies [71, 75, 76, 78]. The latter band is considered to originate from a thin oblate spheroidal morphology, which approximates that of a platelet [71, 88]. Apparently, its aspect ratio is larger than that of the platelet precipitate morphology related with the $1230 \mathrm{~cm}^{-1}$ band.

Returning now to the analysis of our results, we have to state that all the evidence from various studies so far lead us to correlate the $1170 \mathrm{~cm}^{-1}$ band to platelet precipitates, although the 1060 and $1080 \mathrm{~cm}^{-1}$ bands to spheroidal precipitates [72-76]. The band at $1040 \mathrm{~cm}^{-1}$ is just outside the frequency range $\left(1050-1150 \mathrm{~cm}^{-1}\right)$ where spheroidal precipitate bands appear [72]. Previous studies have correlated this band with dendritic or needle-like precipitates [73, 98, 99]. We shall discuss this issue in what follows. Furthermore, a band at $1000 \mathrm{~cm}^{-1}$ detected in our spectra, has not been correlated with any known precipitate morphology.

By considering Eq. 3 the corresponding ratio of frequencies, for the present experimentally detected bands, are $\omega_{1} / \omega_{2}=1.08, \omega_{1} / \omega_{3}=1.10$ and $\omega_{1} / \omega_{4}=1.13$. The theoretically received ratio $\omega_{\text {plat }} / \omega_{\text {sph }}=1.05$ was produced by comparison of Fig. 1(c) and (d), of Ref. 79 and relates the frequency attributed to a platelet precipitate with the corresponding frequency of a spheroidal precipitate. It was previously suggested [71] that the higher the symmetry of a morphology, the lower the frequency of the related IR band or the larger the $\omega_{\text {plat }} / \omega_{\text {sph }}$ ratio. Thus, since the most symmetric shape among all the spheroidal morphologies is the spherical one, which has the lower frequency, it is more likely to connect the ratio $\omega_{1} / \omega_{4}=1.13$ and therefore the $1040 \mathrm{~cm}^{-1}$ band with a structure more close to a spherical morphology. Analogously, the ratio $\omega_{1} / \omega_{3}=1.10$ corresponds to a morphology with lower symmetry than that of $1040 \mathrm{~cm}^{-1}$. To this end the $1060 \mathrm{~cm}^{-1}$ band could be attributed to a structure more close to an octahedral morphology. Similarly, $\omega_{1} / \omega_{2}=1.08$ corresponds to a morphology with even lower symmetry and, therefore, the $1080 \mathrm{~cm}^{-1}$ band could be attributed to a structure more close to a polyhedral morphology. Finally, regarding the $1000 \mathrm{~cm}^{-1}$ band detected in these studies it is not easy to make any assignment. At first, it has not been reported to the best of our knowledge any attribution of such a band to precipitates. Additionally, we notice that the absorption spectra of oxide precipitates in $\mathrm{Si}$ are expected to be located in the Reststrahlen region of the composite, which is between [100, 101] 1000 and $1300 \mathrm{~cm}^{-1}$. Since the $1000 \mathrm{~cm}^{-1}$ value is at the lower limit of the Reststrahlen region it is not prudent to make any attribution and further experimental and theoretical work is necessary to resolve the origin of this band.

Figure 2 displays the variation with temperature of the $\mathrm{O}$ interstitial intensity $\left(1107 \mathrm{~cm}^{-1}\right)$ for the $\mathrm{Cz}-\mathrm{Si}$, the $\mathrm{Cz}-\mathrm{Si}: \mathrm{C}$, the $\mathrm{Cz}-\mathrm{Si}: \mathrm{C}, \mathrm{Sn}_{\mathrm{L}}$ and the $\mathrm{Cz}-\mathrm{Si}: \mathrm{C}, \mathrm{Sn}_{\mathrm{H}}$ samples as well as the variation of the $\mathrm{O}$ precipitation related bands. The purpose is threefold: Firstly, to monitor variations in the evolution of $\mathrm{O}$ in the course of the isochronal anneals, as a result of the presence of $\mathrm{C}$ in the $\mathrm{Cz}$-Si:C in comparison with the $\mathrm{Cz}-\mathrm{Si}$. Secondly, to monitor the variations of $\mathrm{O}$ due the presence of $\mathrm{C}$ and $\mathrm{Sn}$ co-doping in the $\mathrm{Cz}-\mathrm{Si}: \mathrm{C}, \mathrm{Sn}_{\mathrm{L}}$ and the $\mathrm{Cz}-\mathrm{Si}: \mathrm{C}, \mathrm{Sn}_{\mathrm{H}}$ samples. Thirdly, to monitor the evolution of the $\mathrm{O}$ precipitate bands in the various samples.

Noticeably, after the irradiation the spectra of the samples contain various $\mathrm{O}$ and $\mathrm{C}$ related bands. The origin and the behavior of these bands have been studied in detail in our previous studies [102, 103] and will not be considered here. Regarding the evolution of the oxygen band we observe at first that in all the samples there are two stages of decrease as the annealing $\mathrm{T}$ increases. The first stage is in range from RT up to $\sim 700^{\circ} \mathrm{C}$. In this first stage the decrease of the $\mathrm{O}$ concentration is slight but it is larger in the $\mathrm{Cz}-\mathrm{Si}: \mathrm{C}$ sample than that in the $\mathrm{Cz}-\mathrm{Si}$. It is even larger in the $\mathrm{Cz}-\mathrm{Si}: \mathrm{C}, \mathrm{Sn}_{\mathrm{L}}$ and the $\mathrm{Cz}-\mathrm{Si}: \mathrm{C}, \mathrm{Sn}_{\mathrm{H}}$ samples. This stage is certainly related with the formation and transformations of the various radiation defects formed in the course of irradiation (for instance $V O$ and $\mathrm{C}_{\mathrm{i}} \mathrm{O}_{\mathrm{i}}$ ), which upon annealing give rise to larger clusters $[102,103]$. Such clusters are, for instance, the various $V \mathrm{O}_{\mathrm{n}}$ and generally 

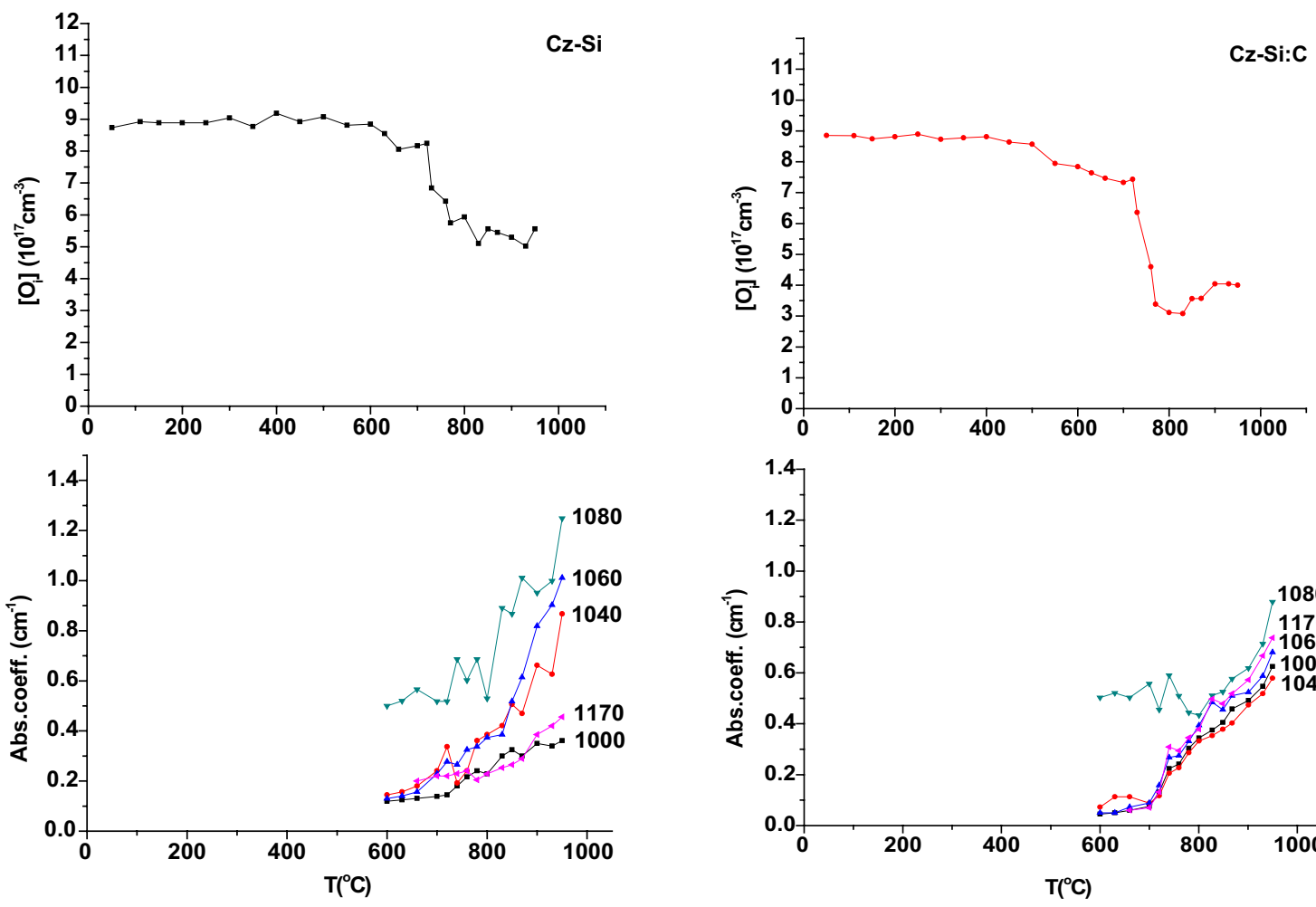

(a)

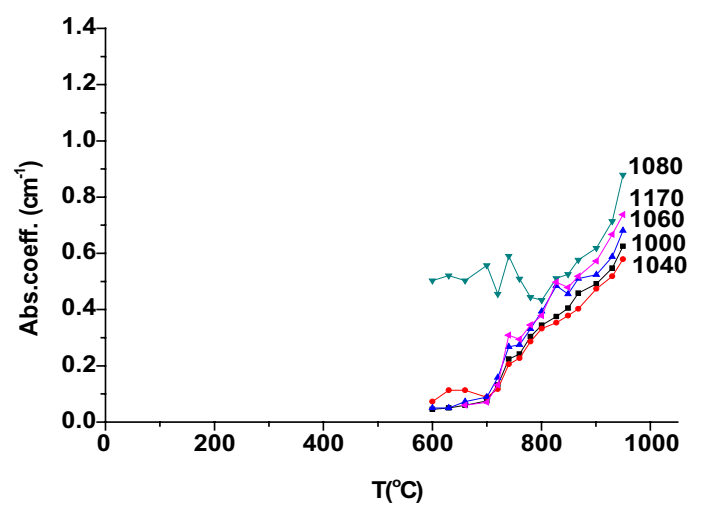

(b)

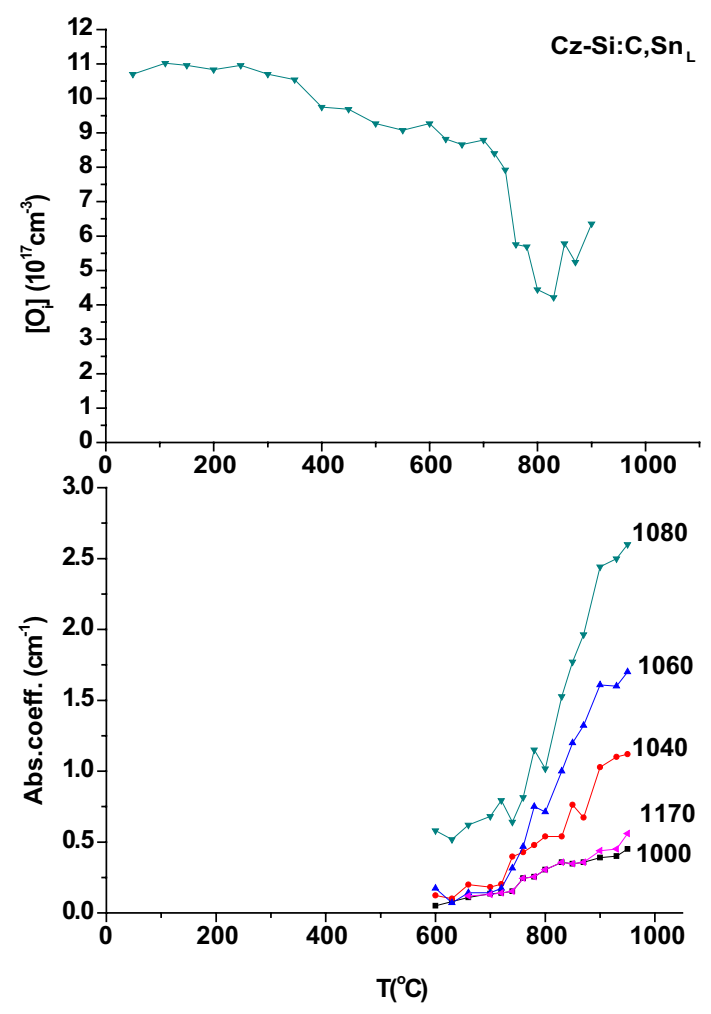

(c)

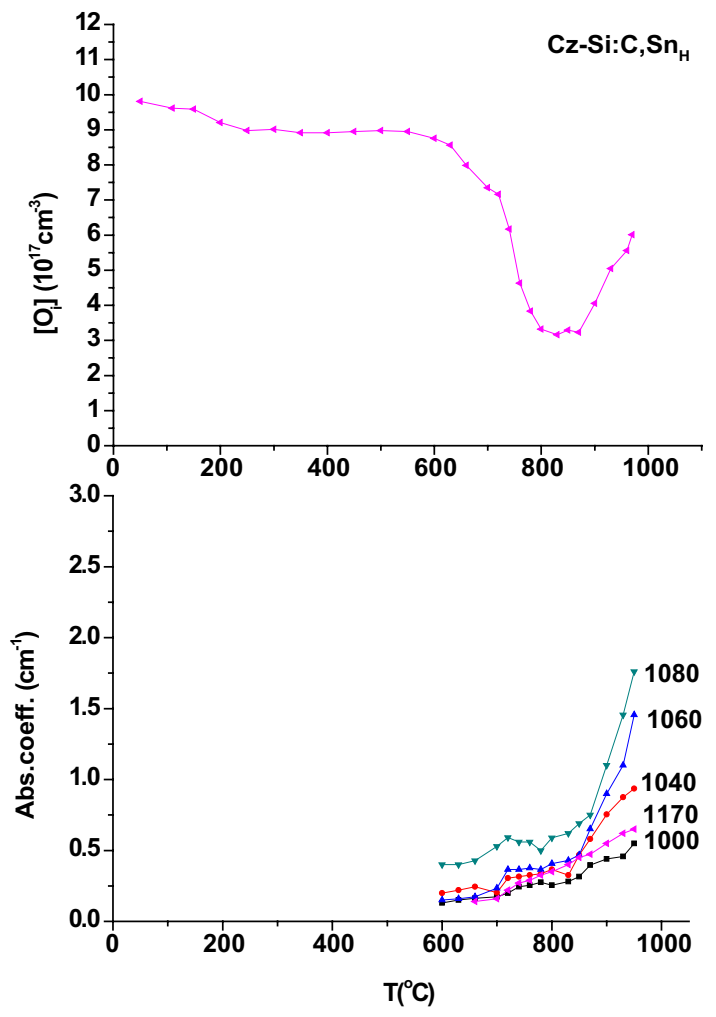

(d)

Fig. 2 The evolution with temperature of the oxygen interstitial band at $1107 \mathrm{~cm}^{-1}$, as well as of the other IR bands at 1000, 1040, 1060, 1080 and $1170 \mathrm{~cm}^{-1}$ representing various oxygen precipitate mor-

phologies for the $\mathrm{Cz}-\mathrm{Si}(\mathbf{a})$, the $\mathrm{Cz}-\mathrm{Si}: \mathrm{C}(\mathbf{b})$, the $\mathrm{Cz}-\mathrm{Si}: \mathrm{C}, \mathrm{Sn}_{\mathrm{L}}(\mathbf{c})$ and the $\mathrm{Cz}-\mathrm{Si}: \mathrm{C}, \mathrm{Sn}_{\mathrm{H}}$ (d) samples, respectively 
$V_{\mathrm{n}} \mathrm{O}_{\mathrm{m}}$ defects as well as carbon-oxygen related defects such as $\mathrm{C}_{\mathrm{i}} \mathrm{O}_{\mathrm{i}}\left(\mathrm{Si}_{\mathrm{I}}\right)_{\mathrm{n}}$ centers. Additionally, at $\sim 450{ }^{\circ} \mathrm{C} \mathrm{O}$ atoms start to diffuse in the Si lattice and begin to aggregate [10, 104] forming initially thermal donors (TDs) and at a later temperature stage $\mathrm{O}$ precipitates. All these processes require the involvement of $\mathrm{O}$, which is reflected in the decrease of $\mathrm{O}$ concentration. When $\mathrm{C}$ is present in the material also carbon-oxygen complexes form [105-107]. Additionally, we note that $C$ enhances [108] the formation of the $V O$ and generally of the $V \mathrm{O}_{\mathrm{n}}$ defects. We also note that $\mathrm{C}$ suppress $[11,12]$ the formation of TDs. Apparently, the reduction in the $\mathrm{O}$ loss due to the suppressed formation of TDs does not compensate for the additional loss of $\mathrm{O}$ due to the enhanced formation of $V \mathrm{O}_{\mathrm{n}}$ complexes and the production of carbon-oxygen defects. Thus, the decrease of $\mathrm{O}$ in this temperature range is found to be larger in the $\mathrm{Cz}-\mathrm{Si}: \mathrm{C}$ than that in the $\mathrm{Cz}-\mathrm{Si}$ sample. This is expected due to the additional interaction between $\mathrm{O}$ and $\mathrm{C}$ in the first sample. In the case now of $\mathrm{C}$ and $\mathrm{Sn}$ co-doping, the presence of Sn makes the situation even more challenging. At first, we note that $\mathrm{Sn}$ generally suppresses $[51,109,110]$ the formation of $V O$, $V \mathrm{O}_{\mathrm{n}}$ as well as the formation $\mathrm{C}_{\mathrm{i}} \mathrm{O}_{\mathrm{i}}$ and $\mathrm{C}_{\mathrm{i}} \mathrm{O}_{\mathrm{i}}\left(\mathrm{Si}_{\mathrm{I}}\right)_{\mathrm{n}}$ defects. Secondly, Sn also suppress [111] the formation of TDs. Additionally, it has been reported [60, 111-114] the formation of $\mathrm{SnVO}$ complexes as well as $\mathrm{Sn}-\mathrm{O}$ pairs. Remarkably, it was suggested [60] that $\mathrm{Sn}-\mathrm{O}$ pairs could serve as nucleation sites for heterogeneous precipitation of $\mathrm{O}$ impurities in $\mathrm{Si}$. Considering all these reactions and processes that $\mathrm{O}$ participates, the $\mathrm{O}$ loss in $\mathrm{C}$ and $\mathrm{Sn}$ co-doping samples $\mathrm{Cz}-\mathrm{Si}: \mathrm{C}, \mathrm{Sn}_{\mathrm{L}}$ and $\mathrm{Cz}-\mathrm{Si}: \mathrm{C}, \mathrm{Sn}_{\mathrm{H}}$ is expected to be larger than that in the $\mathrm{C}$ doping $\mathrm{Cz}-\mathrm{Si}: \mathrm{C}$ sample, a fact verified in our studies (Fig. 2).

In the second stage, in the range between 700 and $800^{\circ} \mathrm{C}$ a large decrease of $\mathrm{O}$ concentration is observed (Fig. 2). This decrease underlines the onset of the main precipitation process and it is manifested by the increase of the various precipitates bands discussed above. By comparing of the evolution curves of the $\mathrm{Cz}-\mathrm{Si}$ and $\mathrm{Cz}-\mathrm{Si}: \mathrm{C}$ samples it is immediately observed that the total $\mathrm{O}$ loss at this temperature range is larger in the $\mathrm{C}$ contained sample. In order to discuss these observations we have to consider the simultaneous evolution of the precipitate bands. As it is immediately seen comparing Fig. 2a, b the strength of the precipitate bands is lower in the $\mathrm{Cz}-\mathrm{Si}: \mathrm{C}$ sample which at first sight is the opposite than that it was expected due to the greater loss of the $\mathrm{O}$ band in $\mathrm{Si}$ in the course of precipitation. Nevertheless, a larger loss of the interstitial O concentration does not necessarily imply an enhancement of the density of precipitates since the $\mathrm{O}$ content undergoes an additional reduction due to the formation of carbon-oxygen complexes [115] as for instance perturbed $\mathrm{C}_{\mathrm{i}} \mathrm{O}_{\mathrm{i}}$ centers $[116,117]$. The loss of $\mathrm{O}$ atoms to unknown sinks cannot be excluded. Furthermore, it has been argued [115] that in high $\mathrm{C}$ and $\mathrm{O}$ material co-precipitates of $\mathrm{SiO}_{2}$ and $\mathrm{SiC}$ may exist. In that case, as $\mathrm{C}$ atoms participate in $\mathrm{O}$ complexes there is an excess of available $\mathrm{Si}_{\mathrm{I}}$ which dissolve existing $\mathrm{O}$ precipitates resulting in their suppression [115]. Considering now the Sn-doped samples, we observe that the intensities of the spheroidal precipitate bands 1040, 1060 and $1080 \mathrm{~cm}^{-1}$ are generally stronger in these samples (Fig. 2c, d) than in the Cz-Si and Cz-Si:C samples (Fig. 2a, b). This can be better seen more clearly by another presentation of the results as in Fig. 3. This figure exhibits, for comparison purposes, the variation of the 1000 (a), 1040 (b), 1060 (c), 1080 (d) and $1170 \mathrm{~cm}^{-1}$ (e) bands respectively for the $\mathrm{Cz}-\mathrm{Si}$, the $\mathrm{Cz}-\mathrm{Si}: \mathrm{C}$, the $\mathrm{Cz}-\mathrm{Si}: \mathrm{C}, \mathrm{Sn}_{\mathrm{L}}$ and the $\mathrm{Cz}-\mathrm{Si}: \mathrm{C}, \mathrm{Sn}_{\mathrm{H}}$ samples that is the evolution of each particular band for all the samples used in this work. A simple inspection shows that the $\mathrm{O}$ precipitate bands at 1040, 1060 and $1080 \mathrm{~cm}^{-1}$ related with spheroidal morphologies are of lower intensity in the $\mathrm{Cz}-\mathrm{Si}: \mathrm{C}$ sample in comparison with the $\mathrm{Cz}-\mathrm{Si}$, $\mathrm{Cz}-\mathrm{Si}: \mathrm{C}, \mathrm{Sn}_{\mathrm{L}}$ and $\mathrm{Cz}-\mathrm{Si}: \mathrm{C}, \mathrm{Sn}_{\mathrm{H}}$ samples. The opposite is observed for the case of the platelet precipitate band at $1170 \mathrm{~cm}^{-1}$. Its intensity is higher in the $\mathrm{Cz}-\mathrm{Si}: \mathrm{C}$ sample than that in the $\mathrm{Cz}-\mathrm{Si}: \mathrm{C}, \mathrm{Sn}_{\mathrm{L}}$ and $\mathrm{Cz}-\mathrm{Si}: \mathrm{C}, \mathrm{Sn}_{\mathrm{H}}$ samples. The intensity is even lower in the $\mathrm{Cz}-\mathrm{Si}$ sample.

At first we observe that in all the samples, both spheroidal and platelet precipitates are found in the spectra. $\mathrm{O}$ precipitation occurs $[49,118-122]$ either by homogeneous or/and heterogeneous nucleation. In the former case, aggregating $\mathrm{O}$ atoms serve as potential sites for nucleation through spherical precipitate nuclei, although in the latter case $\mathrm{O}$ precipitation occurs at heterogeneous sites at various impurities for instance here $\mathrm{C}$ and $\mathrm{Sn}$, as well as point defect clusters for instance $V O$ and $V \mathrm{O}_{2}$ defects and some forms of O-C complexes [49, 116-122]. In general, homogeneous precipitation is expected to lead to spheroidal precipitates although heterogeneous precipitation to lead to platelet precipitates [118-121]. However, the situation is generally more complex, since homogeneous nucleation of platelet precipitates can also occurs [120]. It is therefore evident that in our sample both spheroidal and platelet precipitates are expected to form in the course of annealing of the irradiated material and this is verified in the IR spectra by the presence of bands related to these morphologies.

Let us now discuss our results within the above framework. In the case of the $\mathrm{Cz}-\mathrm{Si}: \mathrm{C}$ sample, the presence of carbon-oxygen centers besides the vacancy-oxygen centers in comparison with the $\mathrm{Cz}$-Si sample, provides additional sites for inhomogeneous nucleation and therefore platelets are expected to have a larger density in this material. This is verified in the spectra by the greater intensity of the corresponding band at $1170 \mathrm{~cm}^{-1}$ (refer to Fig. 3e). In the case of the (C, Sn) co-doped samples the intensity of the platelets band is higher than that of the $\mathrm{Cz}-\mathrm{Si}$ sample but lower than that of the $\mathrm{Cz}-\mathrm{Si}: \mathrm{C}$ sample. Indeed in these $(\mathrm{C}, \mathrm{Sn})$ co-doped 
Fig. 3 The evolution with temperature of the oxygen precipitate bands at $1000(\mathbf{a})$, 1040, (b) 1060 (c), 1080 (d) and $1170 \mathrm{~cm}^{-1}(\mathbf{e})$, respectively for the $\mathrm{Cz}_{-} \mathrm{Si}$, the $\mathrm{Cz}-\mathrm{Si}: \mathrm{C}(\mathbf{b})$, the $\mathrm{Cz}-\mathrm{Si}: \mathrm{C}, \mathrm{Sn}_{\mathrm{L}}(\mathbf{c})$ and the $\mathrm{Cz}$ $\mathrm{Si}: \mathrm{C}, \mathrm{Sn}_{\mathrm{H}}(\mathbf{d})$ samples

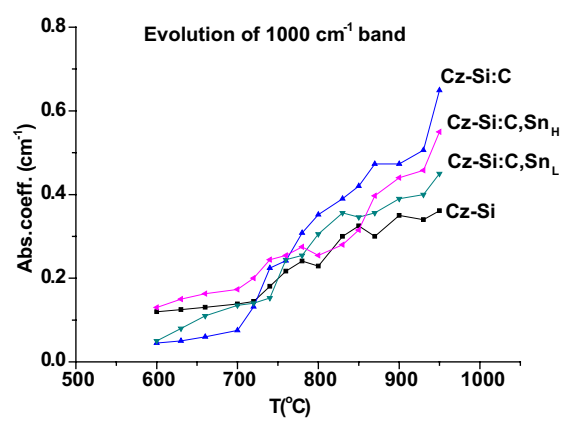

(a)

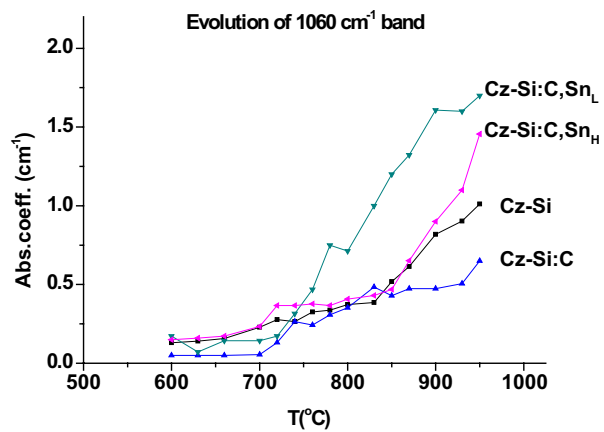

(c)

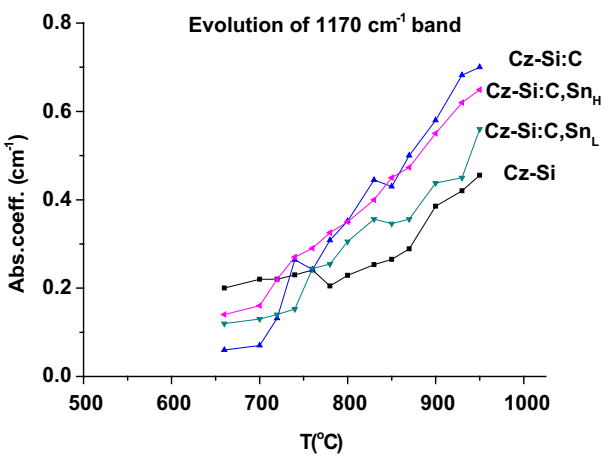

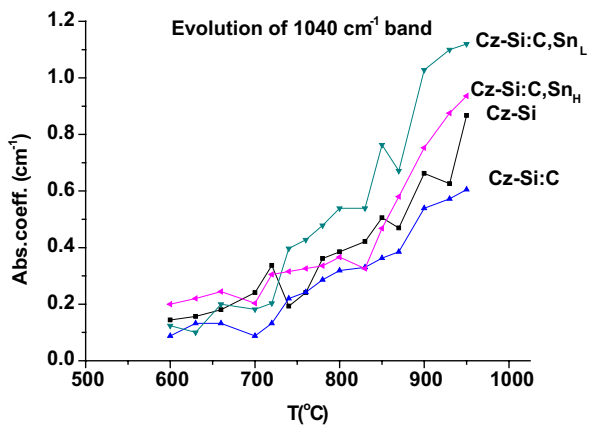

(b)

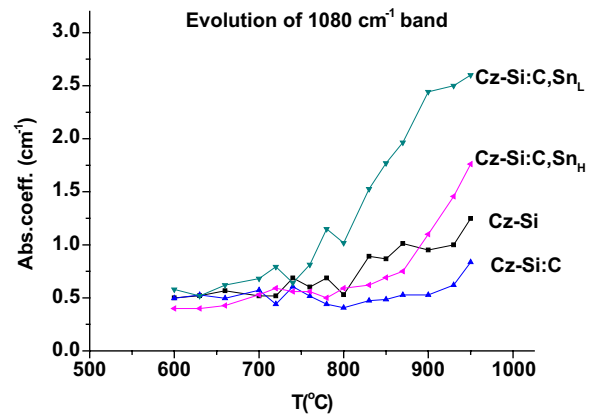

(d)

(e)

samples the additional presence of Sn enhances the number of nucleation sites leading to the formation of more platelets than in the case of the $\mathrm{Cz}-\mathrm{Si}$ sample. However, the intensity of the platelets band in lower in the $(\mathrm{C}, \mathrm{Sn})$ co-doped sample than in the Cz-Si:C sample. Notably, in previous studies $[51,109]$ we have reported that $\mathrm{Sn}$ suppresses the formation of $V \mathrm{O}, V \mathrm{O}_{2}$ and $\mathrm{C}_{\mathrm{i}} \mathrm{O}_{\mathrm{i}}$. pairs. In the case of $\mathrm{Sn}$-doped samples subjected to thermal anneals it is suggested that the competition between $\mathrm{O}$ and $\mathrm{Sn}$ to capture $V$ can lead to a reduction of the number of vacancies bonded to oxygen atoms to form vacancy-oxygen centers. These centers however provide $[48,49]$ nucleation sites mainly for heterogeneous nucleation. Their reduction is reflected in the lower intensity of the $1170 \mathrm{~cm}^{-1}$ band of platelets in the (C, Sn) co-doped samples in comparison with the $\mathrm{Cz}-\mathrm{Si}: \mathrm{C}$ sample. In the case now of the spheroidal precipitate bands at 1040, 1060 and $1080 \mathrm{~cm}^{-1}$ mainly formed through a homogeneous nucleation process, their intensity is clearly lower for the Cz-Si:C sample as compared to the Cz-Si sample (Fig. 3b-d). It has been reported [75] that the amount of spheroidal precipitates is about four times larger than that of the platelet precipitates. Since in the $\mathrm{Cz}$-Si:C sample the $\mathrm{O}$ loss is mainly directed to the formation of platelets, the intensity of the spheroidal bands is lower than that of the Cz-Si sample as observed in Fig. 3b-d. In the case now of the $(\mathrm{C}, \mathrm{Sn})$ co-doped samples both impurities provide nucleation sites which lead [123] to higher precipitate density. In that case the favored morphology is that of a spheroidal precipitate which has a lower interfacial energy than that of a platelet and therefore a lower total free energy [11, 79]. Therefore, the intensities of the spheroidal bands are expected 
to be larger in these samples in agreement with the present study. Furthermore we notice that the intensities of the 1040, 1060 and $1080 \mathrm{~cm}^{-1}$ bands are lower in the $\mathrm{Cz}-\mathrm{Si}: \mathrm{C}, \mathrm{Sn}_{\mathrm{H}}$ than in the $\mathrm{Cz}-\mathrm{Si}: \mathrm{C}, \mathrm{Sn}_{\mathrm{L}}$ sample. This trend is the opposite than that displayed by the platelet precipitate band $1170 \mathrm{~cm}^{-1}$ where its intensity is higher in the $\mathrm{Cz}-\mathrm{Si}$ : $\left(\mathrm{C}, \mathrm{Sn}_{\mathrm{H}}\right)$ sample. In a first approximation, it may be argued that $\mathrm{Sn}$ induces larger strains in the Si lattice of the Cz-Si:Sn ${ }_{\mathrm{H}}$ sample than that of the Cz$\mathrm{Si}: \mathrm{Sn}_{\mathrm{L}}$ sample. It is well established [124] that the smaller the aspect ratio of a precipitate ellipsoid structure, the smaller the strain energy. Thus, the morphology of the platelets precipitates is more favorable to form in the $\mathrm{Cz}-\mathrm{Si}:\left(\mathrm{C}, \mathrm{Sn}_{\mathrm{H}}\right)$ sample in order to decrease the induced strain energy. Correspondingly, the spheroidal morphology is less favorable. This is reflected in our results by the larger intensity of the platelet precipitates and the smaller one of the spheroidal in the case of $\mathrm{Cz}-\mathrm{Si}: \mathrm{C}, \mathrm{Sn}_{\mathrm{H}}$ sample in comparison with the $\mathrm{Cz}-\mathrm{Si}: \mathrm{C}, \mathrm{Sn}_{\mathrm{L}}$ sample. The total number of $\mathrm{O}$ atoms which participate in the precipitation would lead to the formation of both platelets and spheroidal morphologies. Thus, it is expected that when the intensities of the spheroidal morphologies are enhanced then the intensities of the platelets morphologies for the same sample are suppressed, as observed in Fig. 2c, d.

Figure 4 displays the variation with temperature of the intensity of the $\mathrm{C}$ substitutional band $\left(605 \mathrm{~cm}^{-1}\right)$ for the $\mathrm{Cz}$ $\mathrm{Si}: \mathrm{C}$, the $\mathrm{Cz}-\mathrm{Si}: \mathrm{C}, \mathrm{Sn}_{\mathrm{L}}$ and the $\mathrm{Cz}-\mathrm{Si}: \mathrm{C}, \mathrm{Sn}_{\mathrm{H}}$ samples. A simple inspection shows that in the temperature region of $\sim 500$ to $\sim 700^{\circ} \mathrm{C}$, in the course of anneal, the intensity of the $\mathrm{C}$ substitutional band increases gradually and this is an indication of the release of carbon atoms. The phenomenon was also observed previously [125] in irradiated Ge-doped $\mathrm{Si}$ and was connected with the supersaturation of $\mathrm{Si}_{1}$ 's. In particular, the recovery of $\mathrm{C}$ substitutional atoms observed in the spectra by the increase of the intensity of the $605 \mathrm{~cm}^{-1}$ was connected with the formation of $\mathrm{C}_{\mathrm{N}}\left(\mathrm{Si}_{\mathrm{I}}\right)_{\mathrm{M}}$ complexes. These complexes act [66] as sources of these additional $\mathrm{C}$ atoms either involved in reactions with $\mathrm{Si}_{I}$ 's and $V$ or/and transformed to $\mathrm{SiC}$ precipitates. Notably, $\mathrm{C}$ and $\mathrm{Si}_{\mathrm{I}}$ clustering leading in general to the formation of $\mathrm{C}_{\mathrm{N}}\left(\mathrm{Si}_{\mathrm{I}}\right)_{\mathrm{M}}$ complexes has been extensively discussed in the literature [66, 126, 127]. In particular, it was suggested [66] that upon increasing the annealing temperature, various reactions take place involving $V, \mathrm{Si}_{\mathrm{I}}$ as well as $\mathrm{C}_{\mathrm{s}}$ and $\mathrm{C}_{\mathrm{i}}$ leading to the formation of $\mathrm{C}_{\mathrm{N}}\left(\mathrm{Si}_{\mathrm{I}}\right)_{\mathrm{M}}$ complexes. Sources of $V$ are possibly large vacancy clusters [128, 129] and sources of $\mathrm{Si}_{\mathrm{I}}$ 's are possibly large self-interstitial clusters $[130,131]$ present in $\mathrm{Si}$, as a result of anneals. In the case of $\mathrm{Cz}-\mathrm{Si}: \mathrm{C}$ sample the following sequential reactions are envisaged [66] to take place:

$$
\begin{aligned}
& V+\mathrm{Si}_{\mathrm{I}} \rightarrow \varnothing \\
& \mathrm{C}_{\mathrm{N}}\left(\mathrm{Si}_{\mathrm{I}}\right)_{\mathrm{M}}+V \leftrightarrow \mathrm{C}_{\mathrm{N}}\left(\mathrm{Si}_{\mathrm{I}}\right)_{\mathrm{M}-1} \leftrightarrow \mathrm{C}_{\mathrm{N}-1}\left(\mathrm{Si}_{\mathrm{I}}\right)_{\mathrm{M}-1}+\mathrm{C}_{\mathrm{i}}
\end{aligned}
$$

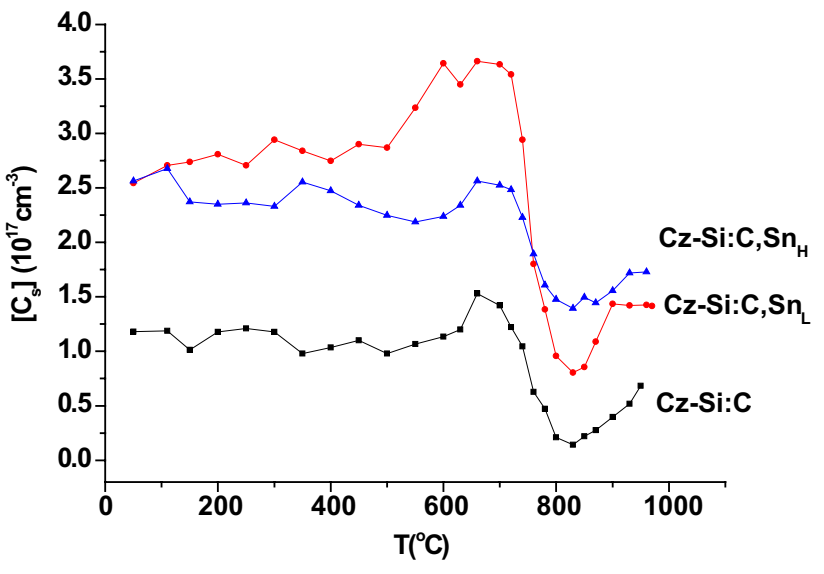

Fig. 4 The evolution with temperature of the carbon substitutional band at $605 \mathrm{~cm}^{-1}$, for the $\mathrm{Cz}-\mathrm{Si}: \mathrm{C}$, the $\mathrm{Cz}-\mathrm{Si}: \mathrm{C}, \mathrm{Sn}_{\mathrm{L}}$ and the $\mathrm{Cz}-$ $\mathrm{Si}: \mathrm{C}, \mathrm{Sn}_{\mathrm{H}}$ samples, respectively

$\mathrm{C}_{\mathrm{i}}+V \leftrightarrow \mathrm{C}_{\mathrm{s}}$

We assume that a number of $V$ survives annihilation according to reaction (4) and these vacancies participate in reactions (5) and (6). Reaction kinetics theory impose [132] that due to the provision of these additional $V$ the equilibrium of the latter reactions shifts in the forward direction. The additional carbon atoms liberated in this way (reactions 5, 6) contribute to the observed increase of the $605 \mathrm{~cm}^{-1}$ band in the $\mathrm{Cz}-\mathrm{Si}$ :C sample. In the case of the $\mathrm{Cz}-\mathrm{Si}: \mathrm{C}, \mathrm{Sn}_{\mathrm{L}}$ sample it is observed that the increase of $\mathrm{C}_{\mathrm{s}}$ is larger than that of the Cz-Si:C sample (Fig. 4). This increase could be understood by considering that the presence of $\mathrm{Sn}$ atoms in the Si lattice suppresses the annihilation rate of $V$ and $\mathrm{Si}_{\text {I }}$ 's in the following way. A fraction of the $V$ is temporarily captured by $\mathrm{Sn}$ atoms forming $\operatorname{Sn} V$ centers which at these temperatures act as transient species. These $V$ do not participate in the annihilation reaction (4), which is therefore retarded. The subsequent release of the $V$ from the temporarily formed $\mathrm{Sn} V$ pairs is then expected to enhance reaction (6). Thus, a larger number of $\mathrm{C}_{\mathrm{s}}$ is produced, reflected to the observed increase of the $605 \mathrm{~cm}^{-1}$ band. In the case now of the $\mathrm{Cz}-\mathrm{Si}: \mathrm{C}, \mathrm{Sn}_{\mathrm{H}}$ sample the increase of $\mathrm{C}_{\mathrm{s}}$ is observed to be substantially lower than that of the $\mathrm{Cz}-\mathrm{Si}: \mathrm{C}, \mathrm{Sn}_{\mathrm{L}}$ sample (Fig. 4). It can be postulated that when the $\mathrm{Sn}$ concentration is particular high, the binding energy of the $\operatorname{Sn} V$ transient species is affected as a result of the enhanced strains induced by the Sn atoms in the Si lattice. This leads to an increase of the survival lifetime of the $\mathrm{Sn} V$ pairs, which in turn leads practically to an increase of the availability of the $\mathrm{Si}_{\mathrm{I}}$ atoms. In this case the corresponding scheme of reactions that govern the phenomenon is:

$$
\begin{aligned}
& \mathrm{C}_{\mathrm{N}} \mathrm{I}_{\mathrm{M}-1}+\mathrm{Si}_{\mathrm{I}} \leftrightarrow \mathrm{C}_{\mathrm{N}}\left(\mathrm{Si}_{\mathrm{I}}\right)_{\mathrm{M}+1} \\
& \mathrm{C}_{\mathrm{N}}\left(\mathrm{Si}_{\mathrm{I}}\right)_{\mathrm{M}+1}+\mathrm{C}_{\mathrm{s}} \leftrightarrow \mathrm{C}_{\mathrm{N}+1}\left(\mathrm{Si}_{\mathrm{I}}\right)_{\mathrm{M}+1}
\end{aligned}
$$


Thus the increase of $\mathrm{C}_{\mathrm{s}}$ in $\mathrm{Cz}-\mathrm{Si}: \mathrm{C}, \mathrm{Sn}_{\mathrm{H}}$ sample is lower than that of the $\mathrm{Cz}-\mathrm{Si}: \mathrm{C}, \mathrm{Sn}_{\mathrm{L}}$ sample. In addition, in the case of $\mathrm{Cz}-\mathrm{Si}: \mathrm{C}, \mathrm{Sn}_{\mathrm{H}}$ sample, some of the $\mathrm{C}_{\mathrm{s}}$ atoms may be captured by $\mathrm{Sn}$ to form $\mathrm{Sn}_{\mathrm{s}} \mathrm{C}_{\mathrm{s}}$ defects as those existed in the $\mathrm{Cz}-\mathrm{Si}: \mathrm{C}, \mathrm{Sn}_{\mathrm{H}}$ sample prior to the irradiation and described in Sect. II.

\section{Conclusions}

FTIR spectroscopy was employed to investigate the impact of Sn doping on the evolution of $\mathrm{O}$ and $\mathrm{C}$ impurities in irradiated Si. Moreover we studied the effect of $\mathrm{C}$ as well as the effect of the $(\mathrm{C}, \mathrm{Sn})$ co-doping on the evolution of the $\mathrm{O}$ precipitates IR bands in the course of isochronal anneals up to $950^{\circ} \mathrm{C}$. By fitting the total free energy curve of a precipitate structure in relation with its aspect ratio it was determined that the more asymmetric the structure, the larger the frequency of the corresponding absorption band, confirming previous reports. We were able to correlate a band at $1170 \mathrm{~cm}^{-1}$ to platelet precipitates and three bands at 1040,1060 and $1080 \mathrm{~cm}^{-1}$ to spheroidal precipitates in general agreement with previous attributions. More specifically, the band at $1040 \mathrm{~cm}^{-1}$ was correlated with a structure more close to a spherical precipitate morphology, the band at $1060 \mathrm{~cm}^{-1}$ more close to an octahedral morphology and the band at $1080 \mathrm{~cm}^{-1}$ more close to a polyhedral morphology. Additionally, it was found that in C containing irradiated material the production of the platelet precipitates is enhanced and the production of the spheroidal ones is reduced, although in $(\mathrm{C}, \mathrm{Sn})$ co-doped irradiated material the opposite behavior was observed. We have suggested that in the case of $\mathrm{C}$ containing $\mathrm{Si}$ the formed nucleation sites favor the formation of platelet precipitates, although in the case of (C, Sn) co-doped Si the enhanced formation of the nucleation sites cause an increase of the interfacial energy of the precipitates which favors spheroidal morphologies. Furthermore, the study of the evolution curve of $\mathrm{C}$ shows a partial recovery prior to the beginning of its complete disappearance. The phenomenon was attributed to the release of $\mathrm{C}$ atoms from $\mathrm{C}_{\mathrm{N}}\left(\mathrm{Si}_{\mathrm{I}}\right)_{\mathrm{M}}$ complexes. In the case of $(\mathrm{C}, \mathrm{Sn})$ co-doping when the $\mathrm{Sn}$ concentration is relatively low, the recovery stage is enhanced in comparison with $\mathrm{C}$-containing $\mathrm{Si}$. The role of $\mathrm{Sn}$ as a temporarily trap of $V$, leading finally to an additional release of $\mathrm{C}$, has been considered as a plausible explanation of the phenomenon. Nevertheless, when the Sn concentration is high, the recovery stage of $\mathrm{C}$ substitutional atoms is partially suppressed. Due to the enhanced strain in the Si lattice, the release of $V$ from the transient $\operatorname{Sn} V$ pairs is affected, leading in essence in a reduction of the annihilation rate between $V$ and $\mathrm{Si}_{\mathrm{I}}$. Consequently, the recovery of $\mathrm{C}$ substitutional atoms is suppressed. Importantly, advances in the knowledge of the mechanisms that isovalent dopants, in particular Sn here, impact the $\mathrm{O}$ and $\mathrm{C}$ precipitation processes leads to a better understanding of the various interactions between the defects involved in the above processes and to the fabrication of improved devices.

Acknowledgements T. Angeletos is grateful to the A.S. Onassis Foundation for financial support through his $\mathrm{PhD}$ scholarship (Grant No. G ZL 001-1/2015-2016). The authors are grateful to Prof. H. Ohyama (Kumamoto National College of Technology, Japan) for the electron irradiations and Profs Neimash and Yamanaka for the provision of the $\mathrm{Cz}-\mathrm{Si}: \mathrm{C}, \mathrm{Sn}_{\mathrm{L}}$ and the $\mathrm{Cz}-\mathrm{Si}: \mathrm{C}, \mathrm{Sn}_{\mathrm{H}}$ sample, respectively.

Open Access This article is distributed under the terms of the Creative Commons Attribution 4.0 International License (http:// creativecommons.org/licenses/by/4.0/), which permits unrestricted use, distribution, and reproduction in any medium, provided you give appropriate credit to the original author(s) and the source, provide a link to the Creative Commons license, and indicate if changes were made.

\section{References}

1. S.G. Cloutier, P.A. Kossyrev, J. Xu, Nat. Mater. 4, 877 (2005)

2. E.N. Sgourou, D. Timerkaeva, C.A. Londos, D. Aliprantis, A. Chroneos, D. Caliste, P. Pochet, J. Appl. Phys. 113, 113506 (2013)

3. H. Chroneos, R.W.G. Bracht, B.P. Uberuaga, Mater. Sci. Eng. B 154-155, 72 (2008)

4. A. Chroneos, C. A. Londos, J. Appl. Phys. 107, 093518 (2010)

5. H. Wang, A. Chroneos, C.A. Londos, E.N. Sgourou, U. Schwingenschlogl. Appl. Phys. Lett. 103, 052101 (2013)

6. L.I. Murin, E.A. Tolkachava, V.P. Markevich, A.R. Peaker, B. Hamilton, E. Monakhov, B.G. Svensson, J.L. Lindström, P. Santos, J. Coutinho, A. Carvalho, Appl. Phys. Lett. 98, 182101 (2011)

7. A. Chroneos, R.W. Grimes, H. Bracht, J. Appl. Phys. 105, 016102 (2009)

8. A. Chroneos, C. Skarlatos, C. Tsamis, A. Christofi, D.S. McPhail, R. Huang, Mater. Sci. Semicond. Proc. 9, 640 (2006)

9. R. C. Newman, R. Jones, in Oxygen in Silicon, Semiconductors and Semimetals, vol. 42, ed. by F. Shimura (Academic Press, Orlando, 1994), p. 289

10. H. Bender, J. Vanhellemont, in Handbook on Semiconductors, Materials, Properties and Preparations, vol. 3b, ed. by T.S. Moss, S. Mahajan (Elsevier, North-Holland, Amsterdam, 1994), p. 1637

11. A. Borghesi, B. Pivac, A. Sassella, A. Stella, J. Appl. Phys 77, 4169 (1995)

12. G. Davies, R.C. Newman, in Handbook on Semiconductors, Materials, Properties and Preparations, vol. 3b, ed. by T.S. Moss, S. Mahajan (Elsevier, North-Holland, Amsterdam, 1994), p. 1557

13. C.A. Londos, M.S. Potsidi, V.V. Emtsev, Phys. Stat. Solidi C 2, 1963 (2005)

14. W. Scorupa, R.A. Yankov, Mater. Chem. Phys. 44, 101 (1996)

15. G.D. Watkins, J.W. Corbett, Phys. Rev. 138, A543 (1965)

16. T. Hallberg, J.L. Lindström, J. Appl. Phys. 72, 5130 (1992)

17. C. Cui, D. Yang, X. Ma, R. Fan, D. Que, Phys. Stat. Solidi A 202, $2442(2005)$

18. I. Yonenaga, T. Taishi, K. Inoue, R. Gotoh, K. Kutsukake, Y. Tokumoto, Y. Ohno, J. Cryst. Growth 395, 94 (2014) 
19. Y.V. Pomozov, M.G. Sosnin, L.I. Khirunenko, V.I. Yashnik, Semiconductors 34, 994 (2000)

20. X. Xhu, Yu, D. Yang, J. Cryst. Growth 401, 141 (2014)

21. X. Yu, J. Chen, X. Ma, D. Yang, Mater. Sci. Eng. R 74, 1 (2013)

22. J. Vanhellemont, X. Zhang, W. Xu, J. Chen, X. Ma, D. Yang, J. Appl. Phys 108, 123501 (2010)

23. J. Vanhellemont, M. Suezawa, I. Yonenaga, J. Appl. Phys 108, 016105 (2010)

24. K. Sumino, I. Yonenaga, in Oxygen in Silicon, Semiconductors and Semimetals, vol. 42, ed. by F. Shimura (Academic Press, Orlando, 1994), p. 450

25. H. Tsuya, in Oxygen in Silicon, Semiconductors and Semimetals, vol. 42, ed. by F. Shimura (Academic Press, Orlando, 1994), p. 619

26. A. Chroneos, E.N. Sgourou, C.A. Londos, U. Schwingenschlögl, Appl. Phys. Rev. 2, 021306 (2015)

27. H. Shimura, Tsuya, T. Kawamura, J. Appl. Phys. 51, 269 (1980)

28. C. Claeys, E. Simoen, V.B. Neimash, A. Kraitchinskii, M. Krasko, O. Puzenko, A. Blondeel, P. Clauws, J. Electrochem. Soc. 148, G738 (2001)

29. J.D. Murphy, K. Bothe, M. Olmo, V.V. Voronkov, R.J. Falster, ECS Trans. 33, 121 (2010)

30. M. Akatsuka, K. Sueoka, N. Adachi, N. Morimoto, H. Katahama, Microelectron. Eng. 56, 99 (2001)

31. K.F. Kelton, Phil. Trans. R. Soc. Lond. A 361, 429 (2003)

32. O.De.. Gryse, P. Clauws, J. Van. Landuyt, O. Lebedev, C. Claeys, E. Simoen, J. Vanhellemont, J. Appl. Phys. 91, 2493 (2002)

33. P. Gaworzewski, E. Hild, F.-G. Kirscht, L. Vecsernyes, Phys. Stat. Solidi A 85, 133 (1984)

34. K. Tempelhhoff, F. Spiegelberg, R. Gleichmann, D. Wruck, Phys. Stat. Solidi A 56, 213 (1979)

35. U. Gösele, MRS 59, 419 (1986)

36. J.-Y. Huh, U. Gösele, T.Y. Tan, J. Appl. Phys. 78, 5926 (1995)

37. P. Liu, X. Ma, J. Zhang, L. Liand, D. Que, J. Appl. Phys. 87, $3669(2000)$

38. R.F. Hafer, T.S. Moss, Semicond. Sci. Technol. 22, 179 (2007)

39. R. Romanyak, V. Melnic, V. Babich, V. Kladko, O. Gudymenko, V. Ilchenko, L. Lasyliev, A. Goriachko, Nanoscale Res. Lett. 9, 693 (2014)

40. G.D. Watkins, J.W. Corbett, Phys. Rev. 121, 1001 (1961)

41. L.I. Murin, J.L. Lindström, B.G. Svensson, V.P. Markevich, A.R. Peaker, C.A. Londos, Solid State Phenom. 108-109, 267 (2005)

42. N.V. Sarlis, C.A. Londos, L.G. Fytros, J. Appl. Phys. 81, 1645 (1997)

43. C.A. Londos, M. Potsidi, E. Stakakis, Physica B 340-342, 551 (2003)

44. H. Wang, A. Chroneos, C.A. Londos, E.N. Sgourou, U. Schwingenschlögl, Sci. Rep. 4, 4909 (2014)

45. R.C. Newman, J. Phys. 12, R335 (2000)

46. K. Sueoka, E. Kamiyama, P. Spiewak, J. Vanhellemont, J. Solid State Sci. Technol. 5, P3176 (2016)

47. V.V. Voronkov, R. Falster, Solid State Phenom. 178-179, 3 (2011)

48. V.V. Voronkov, R. Falster, J. Appl. Phys 91, 5802 (2002)

49. V.V. Voronkov, R. Falster, J. Electrochem. Soc 149, G167 (2002)

50. A. Brelot, IEEE Trans. Nucl. Sci. 19, 220 (1972)

51. A. Chroneos, C.A. Londos, E.N. Sgourou, J. Appl. Phys. 110, 093507 (2011)

52. G.D. Watkins, Phys. Rev. B 12, 4383 (1975)

53. E. Simoen, C. Claeys, V. Privitera, S. Coffa, M. Kokkoris, E. Kossionides, G. Fanourakis, A. Nylandsted Larsen, P. Clauws, Nucl. Instrum. Meth. Phys. Res. B 186, 19 (2002)
54. F. Lemeilleur, G. Linström, S. Watts, 2nd RD48 status report. CERN/LHCC Rep. 98-39, 1 (1998)

55. G. Linström, M. Moll, E. Fretwurst, Nucl. Istrum. Meth. Phys. Res. A 426, 1 (1999)

56. T. Angeletos, E.N. Sgourou, A. Andrianakis, A. Diamantopoulou, A. Chroneos, C.A. Londos, J. Appl. Phys. 118, 015704 (2015)

57. V.B. Neimash, A. Kraitchinskii, M. Kras'ko, O. Puzenko, C. Claeys, E. Simoen, B. Svensson, A. Kuznetsov, J. Electrochem. Soc. 147, 7227 (2000)

58. L.I. Khirunenko, Y.V. Pomozov, M.G. Sosnin, Solid State Phenom. 82-84, 111 (2002)

59. W. Wijaranakula, J. Appl. Phys. 69, 2737 (1991)

60. W. Wijaranakula, J. Appl. Phys. 72, 2713 (1992)

61. K. Sueoka, E.E. Kamiyama, P. Spiewak, J. Vanhellemont, ECS J. Solid State Sci. Technol. 5, P3176 (2015)

62. A. Carvalho, R. Jones, Silicon, Germanium, and Their AlloysGrowth, Defects, Impurities and Nanocrystals, Chap. 4, (CRC Press, Boca Raton, 2014)

63. E. Kamiyama, K. Sueoka, J. Vanhellemont, Silicon, Germanium, and Their Alloys-Growth, Defects, Impurities and Nanocrystals, Chap. 5, (CRC Press, Boca Raton, 2014)

64. K. Sueoka, N. Ikeda, T. Yamamoto, S. Kobayashi. J. Appl. Phys. 74, 5437 (1993)

65. U. Gösele, P. Laveant, N. Engler, P. Werner, MRS 610, B7.1.1 (2000)

66. R. Pinacho, P. Castrillo, M. jaraiz, I. Martin-Bragado, J. Barbola, H.-J. Gossmann, G.-H. Gilmer, J.L. Benton, J. Appl. Phys. 92, 1582 (2002)

67. S. Mirabella, A. Coati, D. De Salvador, E. Napolitani, A. Matoni, G. Bisognin, M. Berti, A. Carnera, A.V. Drigo, S. Scalese, S. Pulvirenti, A. Terrasi, F. Priolo, Phys. Rev. B 65, 045209 (2002)

68. V.V. Emtsev, Jr., C.A.J. Ammerlaan, V.V. Emtsev, G.A. Oganesyan, B.A. Andreev, D.F. Kuritsin, A. Misiuk, B. Surma, C.A. Londos, Phys. Stat. Solidi B 235, 75 (2003)

69. A. Misiuk, J. Bac Misiuk, A. Barch, A. Romano, M. Rodriguez, I.V. Antonova, V.P. Popov, C.A. Londos, J. Jun, Int. J. Hydrogen Energy 26, 483 (2001)

70. V.V. Voronkov, Private communication

71. A. Borghesi, A. Sassella, P. Geranzani, M. Porrini, B. Pivac, Mat. Sci. Eng. B 73, 145 (2000)

72. A. Sassella, A. Borghesi, G. Borionetti, P. Geranzani, Mater. Sci. Eng. B 73, 224 (2000)

73. D. Kot, G. Kissinger, M.A Schubert, A. Sattler, ECS J Sol. State Sci. Technol. 3, P370 (2014)

74. T. Halberg, J.L. Lindstrom, J. Appl. Phys 72, 5130 (1992)

75. Q. Ma, Y. Li, S. Yang, H. Liu, Q. Hao, Mater. Sci. Eng. B 122, $218(2005)$

76. Q.-Y. Ma, Y.-X. Li, G.-F. Chen, S. Yang, L.-L. Liu, P.-J. Niu, D.-N. Chen, H.-T. Li, Chin. Phys. 14, 1882 (2015)

77. S.M. Hu, J. Appl. Phys 51, 5945 (1980)

78. A. Sassella, A. Borghesi, P. Geranzani, G. Borionetti, Appl. Phys. Lett. 75, 1131 (1999)

79. V.V. Voronkov, R. Falster. J. Appl. Phys. 89, 5965 (2001)

80. J. D. Eshelby, Proc. R. Soc. Lond. A 241, 376 (1957)

81. F.M. Livingston, S. Messoloras, R.C. Newman, B.C. Pike, R.J. Stewart, N.J. Binns, W.P. Brown, J.G. Wilkes, J. Phys. C 17, $6253(1984)$

82. J. Cheung, S. Messoloras, S. Rycroft, R.J. Stewart, M.J. Binns, Semicond. Sci. Technol. 15, 782-788 (2000)

83. K. Wada, H. Nakanishi, H. Takaoka, N. Innoue, J. Cryst. Growth 57, 535 (1982)

84. K. Wada, N. Innoue, K. Kohra, J. Cryst. Growth 49, 479 (1980)

85. K. Sueoka, M Akatsuka, M. Yonemura, T. Ono, E. Asayama, Y. Koike, S. Sadamitsu, Solid State Phenom. 82-84, 49 (2002) 
86. F.S. Ham, J. Phys. Chem. Solids 6, 335 (1958)

87. C.Y. Kung, J. Appl. Phys. 65, 4654 (1989)

88. D. Kot, G. Kissinger, M.A. Schubert, M. Klingsporn, A. Huber, A. Sattler, Phys. Status Solidi RRL 9, 405 (2015)

89. F. Zeller, C. Wurtser, K. Laßmann, W. Eisenmenger, Mater. Sci. Forum 258-263, 399 (1997)

90. C.Y. Kung, Jpn. J. Appl. Phys. 31, 2846 (1992)

91. D. Kot, G. Kissinger, M.A. Schubert, M. Klingsporn, A. Sattler, J. Solid States Sci. Technol. 3, 370 (2014)

92. H. Fujimory, J. Electrochem. Soc. 144, 9 (1997)

93. S. Zhang, M. Juel, E. J. Ovrelid, G. Tranell, J. Gryst. Growth 411, 63 (2015)

94. S. Hahn, M. Arst, K.N. Ritz, S. Shatas, H.J. Stein, Z.U. Rek, W.A. Tiller, J. Appl. Phys. 64, 849 (1988)

95. H.L. Tsai, in Semiconductor Silicon 1986, ed. by H.R. Huff, T. Abe, B. Kolbesen (The Electrochemical Society, Pennington, 1986), p. 790

96. S. Kishino, Y. Matsushita, M. Kanamori, T. Iizuka, Jpn. J. Appl. Phys. 21, 1 (1982)

97. J.P.N.N. Nagasima, J. Appl. Phys 9, 879 (1970)

98. D. Kot, Influence of vacancies introduced by RTA on the nucleation, size, morphology, and gettering efficiency of oxygen precipitates in silicon wafers, $\mathrm{PhD}$ Thesis, Brandenburg University of Technology Cottbus-Senftenberg (2013)

99. L.I. Murin, J.L. Lindstrom, V.P. Markevich, A. Misiuk, C.A. Londos, J. Phys. 17, 2237 (2005)

100. O. De Gryse, P. Clauws, O. Lebedev, J. Van Landuyt, J. Vanhellemont, C. Claeys, E. Simoen, Physica B 308-310, 294 (2001)

101. O. De Gryse, J. Vanhellemont, P. Clauws, O. Lebedev, J. Van Landuyt, E. Simoen, C. Claeys, Physica B 340-342, 1003 (2003)

102. C.A. Londos, E.N. Sgourou, A. Chroneos, V.V. Emtsev. Semicond. Sci. Technol. 26, 105024 (2011)

103. C.A. Londos, D. Aliprantis, E.N. Sgourou, A. Chroneos, P. Pochet, J. Appl. Phys 111, 123508 (2012)

104. V.V. Voronkov, R. Falster, Phys. Stat. Solidi B 252, 816 (2015)

105. J.L. Linström, H. Weman, G.S. Oehrlein, Phys. Stat. Solidi A 99, 581 (1987)

106. K.A. Fukuoka, M. Honda, Jpn. J. Appl. Phys. 29, 1625 (1990)

107. R. Bean, R.C. Newman, J. Phys. Chem. Solids 33, 255 (1972)

108. C.A. Londos, E.N. Sgourou, A. Chroneos, J. Mater. Sci. Mater. Electron. 25, 4872 (2014)

109. A. Chroneos, C.A. Londos, E.N. Sgourou, P. Pochet, Appl. Phys. Lett. 99, 241901 (2011)
110. C.A. Londos, E.N. Sgourou, D. Hall, A. Chroneos, J. Mater. Sci. Mater. Electron. 25, 2395 (2014)

111. V.B. Neimash, A. Kraitchinskii, M. Kras'ko, O. Puzenko, C. Claeys, E. Simoen, B. Svensson, A. Kuznetsov, J. Electrochem. Soc. 147, 2727 (2000)

112. L.I. Khirunenko, O. Kobzar, Y.V. Pomozov, M.G. Sosnin, N.A. Tripachko, V.P. Markevich, L.I. Murin, A.R. Peaker, Phys. Stat. Solidi C 0, 694 (2003)

113. C. Gao, X. Ma, J. Zhao, D. Yang, J. Appl. Phys 113, 093511 (2013)

114. C. Gao, X. Ma, D. Yang, Phys. Stat. Solidi A 210, 2199 (2013)

115. C. Claeys, J. Vanhellemont, Solid State Phenom. 6-7, 21 (1989)

116. F. Shimura, J.P. Balardo, P. Fraundorf, Appl. Phys. Lett. 46, 941 (1985)

117. F. Shimura, J. Appl. Phys. 59, 3251 (1986)

118. C. Maddalon-Vinande, J.P. Vallard, D. Barbier, J. Electrochem. Soc. 142, 2071 (1995)

119. A. Bourret, Mater. Res. Soc. 59, 223 (1986)

120. G. Kissinger, Oxygen Precipitation in Silicon in Defects and Impurities in Si Materials, ed. by Y. Yoshida, G. Langouche, (Springer, Berlin, 2015), p. 273

121. G. Kissinger, G. Dabrowski, A. Slatter, C. Serving, T. Muller, H. Richter, W. von Ammon, J. Electrochem. Soc. 154, H454 (2007)

122. R. Falster, V.V. Voronkov, F. Quast, Phys. Stat. Solidi B 222 , 219 (2000)

123. K. Yasutake, M. Umeno, H. Kawabe, Phys. Stat. Solidi A 88, 207 (1984)

124. G. Kissinger, J. Dabrowski, T. Sinno, Y. Yang, D. Kot, A. Sattler, J. Cryst. Growth. doi:10.1016/j.jcrysgro.2016.10.073

125. C.A. Londos, A. Andrianakis, V. Emtsev, H. Ohyama, J. Appl. Phys. 105, 123508 (2009)

126. A. Mattoni, F. Bernardini, L. Colombo, Phys. Rev. B 66, $195214(2002)$

127. S.S. Kapur, M. Prasad, T. Sinno, Phys. Rev. B 69, 155214 (2004)

128. J.L. Hastings, S.K. Estreicher, P.A. Fedders, Phys. Rev. B 56, 10215 (1999)

129. M. Prasad, T. Sinno, Phys. Rev. B 68, 045206 (2003)

130. S.S. Kapur, T. Sinno, Phys. Rev. B 82, 045205 (2010)

131. S. Lee, G.S. Hwang, Phys. Rev. B 78, 045204 (2008)

132. P.W. Atkins, Physical Chemistry. (Oxford University Press, Oxford, 1994) 